\title{
Aspects of Modality in Russian Songs of Northern Lake Onega, North-west Russia
}

The regions around Lake Onega (Figure 1) were already populated in the Mesolithic era and by language the Onega dwellers seem to have been Proto-Finno-Ugrians the past 7000 years or more (Patrushev 2000, 37; 53-58; Wiik 2000). Because the wind caused the waves of this huge lake to roar on the shore, Finnic speakers ${ }^{1}$ called it $\ddot{A} \ddot{a n i n e n}$ 'the Sounding one' and Ä̈̈nisjärvi 'Sounding Lake'. It was about a millennium ago when the speakers of East-Slavic started to appear in this region. In their language $\ddot{A} \ddot{a n n i-n e n}$ transformed to Oné-žkoe and the lake is known as Onega in modern Russian. The northern parts of the lake are called Transonegan by Russian researchers.

This paper is a modal analysis of some Transonegan songs sung by local Russians. My source is the wonderful collection of melodies called Pesni zaonež'ja v zapisjah 1880-1980 godov 'Transonegan Songs Written Down from 1880 to 1980' (Krasnopol'skaja 1987), carefully edited by Tamara V. Krasnopol'skaja, a musicologist in Petrozavodsk. The publication contains 110 transcriptions of Russian folk song, and the editor has arranged the tunes in seven sections seen below. For more detailed data on laments, see the following study by Larisa Leisiö.

\footnotetext{
I) Phonogrammed or tape recorded drawn-out songs from 1926 and 1976-1985 $(\Sigma=30)$ :

Transcriptions I. 1-30

II) Some variants of the former drawn-out songs from 1916 (originally from $1886[\Sigma=11]$ ):

Transcriptions II. 1a-28a

III) Ritual farewell songs [of the bride] at weddings from $1886,1916,1926$, and 1976-1985 ( $\Sigma=12)$ :

Transcriptions III. 31-42

IV) Ritual wedding songs of praise from 1886, 1916, 1926, and 1976-1985 $(\Sigma=22)$ :

Transcriptions IV. 43-64
}

\footnotetext{
1 Finno-Ugric is a linguistic family spoken by peoples representing quite a variety of anthropological features in Europe. For instance, the Saame and Finns are closely related to the prehistoric Cro-Magnon man while the Maris (Cheremisses) and Hungarians have relatively recent features inherited from their Turkic neighbours. Finnic or Baltic Finnic is used to refer to western Finno-Ugrians (Karelians, Vepsians, Estonians, Finns etc - but not the Saame) living to the east of the Baltic Sea.
} 
V) Youth songs for games and evening parties from 1916, 1926 and 1976-1985 $(\Sigma=7)$ :

VI) Dance songs from 1886, 1916, 1926, and 1976-1985 $(\Sigma=10)$ :

VII) Wedding laments from $1886,1975-1986(\Sigma=18)$ :
Transcriptions V. 65-71

Transcriptions VI. 72-73

Transcriptions VII. 1-18

The drawn-out song (protjažnye pesni, see Zemcovsky 1967; in Finnish the term means 'verkalleen venytelty laulu') of Section I is a Russian genre of lyrical tunes having a free meter materialised by singers through the interplay of syllabic and melismatic treatment of text. Some researchers presume that the genre "evolved simultaneously with Russian liturgical music during the 14th to 17th centuries, when the Russian nation formed" (Zemtsovsky 2000, 765). Krasnopol'skaja formed Section II of this genre because the transcriptions were made in 1916 according to how Mr. V. Lysanov, a local merchant and an admirer of the local style, remembered them from the 1880s. The songs of Section III are wedding songs belonging to the rituals during which the bride bade farewell to her home village, maidenhood and freedom before leaving her home for the village and family of her newly wedded husband. Section IV is of wedding songs sung when praising the groom and his family at the home of the bride. The melodies in Section $V$ were courting songs of a youth sung mainly during the evening parties arranged in the fall time while the maidens were spinning and doing handicraft. Section VI is of dances accompanied by singing. The final section, the wedding laments, are an appendix to this collection but they are referred to by the present author with number VII. These laments were sung only in the bride's home and village.

\section{Question, Aim, Method}

Any Russian listener experiences the Transonegan songs as truly Russian. However, it is not simple to offer explanations for what then makes these songs so Russian in the first place? One purpose is to make an analysis of one local tradition to offer some answers. However, the present analysis has only modal features as the focus interpretations are carried out through the Lükő Theory (Lükö 1964; 1965), the nucleus of which is that the archaic melodies of the Indo-European (= IE) populations are based on six specific pentatonic root modalities (five being hemitonic) while the archaic modalities of the Finno-Ugric populations were anhemitonic pentatonic.

The author is totally conscious of the fact that the reader will have difficulties in following the text. The Lükö Theory has been tested by the author with many kinds of material, only some part of the results having been published (see e.g. Leisiö 1999a-b; 2000a-b). The reader must first understand that, according to the present author, the modal basis of tonal music emerged during the Middle Ages among the West-European 


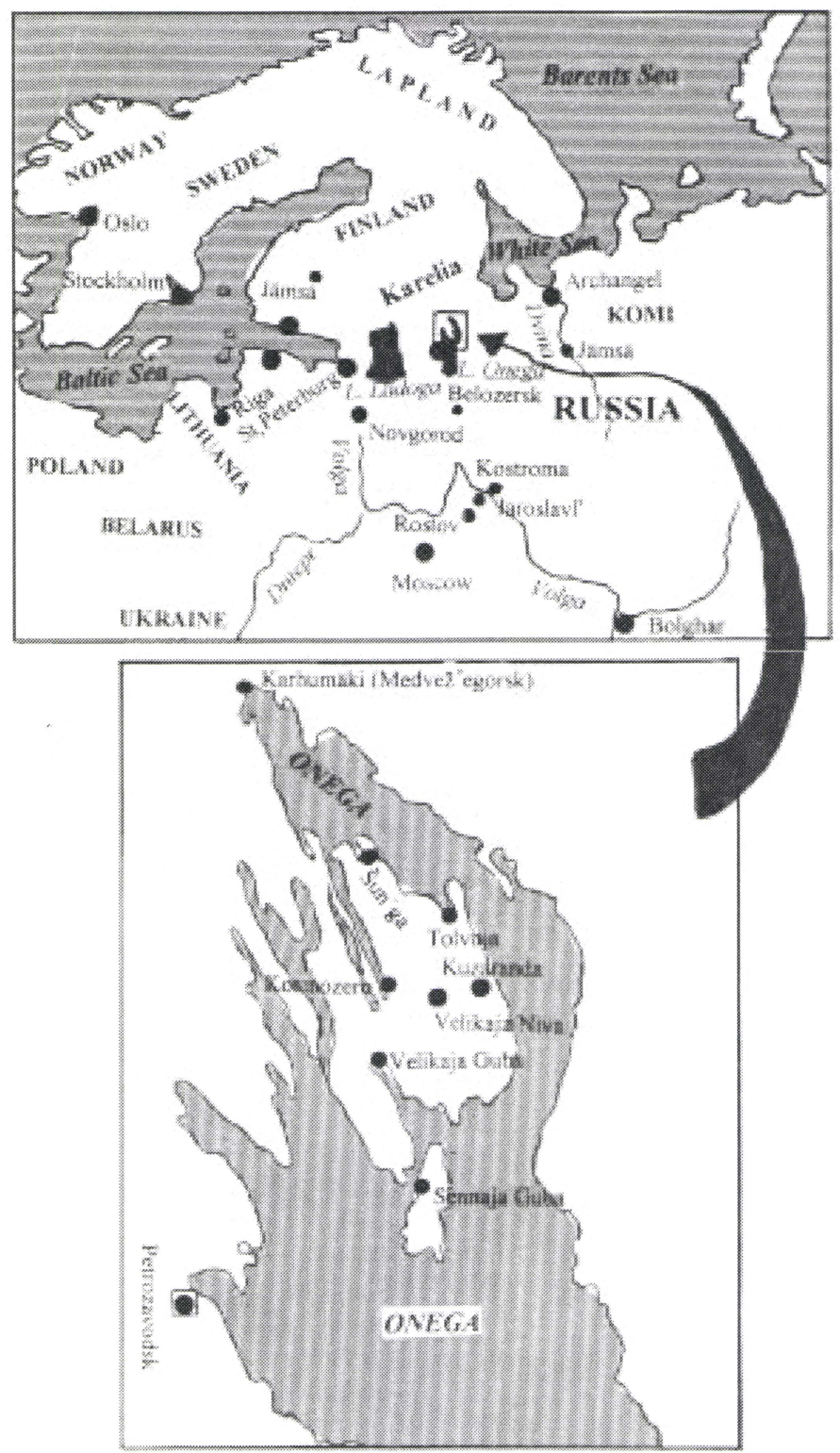

Figure 1. The location of Lake Onega in Northwest Russia and the northern part of the lake with some of the villages mentioned in the text.

peasant cultures. As a result the three prime modalities in tonal tradition, the major, natural minor and harmonic minor, are heptatonic derivatives of three separate pentatonic parent modes going back to the Neolithic time of Proto-Indo-European (PIE) populations, but, presumably, even further back to their Mesolithic ancestors. 
The PIE Roots in $g^{1}$. The pentatonic degrees in descending order

\begin{tabular}{l|lllllll} 
& $5^{2}$ & $¥$ & 1 & 2 & 3 & 4 & 5 \\
\hline PIE Root $g^{1} 6-I^{\mathrm{GL}}:$ & $g^{2}$ & $f^{2}$ & $e^{2}$ & $d^{2}$ & $c^{2}$ & $b^{1}$ & $\underline{G}^{1}$ \\
PIE Root $g^{1} 6-I I^{\mathrm{GL}}:$ & $g^{2}$ & $f^{2}$ & $e^{2}$ & $d^{2}$ & $c \#^{2}$ & $b^{1}$ & $\underline{G}^{1}$ \\
PIE Root $g^{1} 6-I I I^{\mathrm{GL}}:$ & $g^{2}$ & $f^{2}$ & $e^{2}$ flat & $d^{2}$ & $c^{2}$ & $b^{1}$ & $\underline{G}^{1}$ \\
PIE Root $g^{1} 6-I V^{\mathrm{GL}}:$ & $g^{2}$ & $f^{2}$ & $e^{2}$ flat & $d^{2}$ & $c^{2}$ & $b^{1}$ flat & $\underline{G}^{1}$ \\
PIE Root $g^{1} 6-V^{\mathrm{GL}}:$ & $g^{2}$ & $f^{2}$ & $e^{2}$ flat & $d^{2}$ flat & $c^{2}$ & $b^{1}$ flat & $\underline{G}^{1}$ \\
PIE Root $g^{1} 6-V I^{\mathrm{GL}}:$ & $g^{2}$ & $f^{2}$ & $e^{2}$ & $d^{2}$ & $c^{2}$ & $b^{1}$ flat & $\underline{G}^{1}$ \\
\hline
\end{tabular}

Table 1. The Proto-Indo-European pentatonic Root Modalities according to Gábor Lükő (GL) symbolised by Roman figures I-VI. The Pentatonic basic tone is $g^{1}$ corresponding to degree number 5 . Each root may occasionally have an auxiliary tone $¥\left(f^{2}\right)$ between the degrees $5^{2}$ and 1 . The melodic progression 3-4-5 or 5-4-3 is called the Pentatonic marker because it quite openly flags the presence of an Indo-European style. The $¥$ makes the mode hexachordic (referred to with $g^{1} 6-I V^{\mathrm{GL}}$ etc.) but in spite of this, the musical logic governing the movements of melody remains pentatonic. Except for the anhemitonic Root $V I^{\mathrm{GL}}$, all the others are hemitonic. The six are clearly different by structure and emotion from the anhemitonic modal system of $d o, r e, m i, ~ s o l, ~ l a$, familiar to Chinese and Turkic musics but also characteristic of the archaic styles of the Saame and other Finno-Ugrians.

In 1964 Gábor Lükö suggested that it was possible to discern six different root modalities in the most archaic song traditions of the Indo-European peoples (Table 1). It is most crucial to understand that in each of the six roots the Pentatonic basic tone corresponds to the 5 th degree, or the Dominant, of tonal modes. The finale of these pentatonic melodies may be any of the five pentatonic degrees. It seems, however, that ever since the medieval records (such as the transcriptions of troubadour melodies) it was often the 3 rd degree which was chosen as the final tone. Another feature is that the singers embellished the tunes with an auxiliary tone $¥$ inserted between the pentatonic degrees 1 and $5^{2}$. Because the most archaic Indo-European melodies clearly have a descending direction in melody line, the numerical sequence of degrees are also given in descending order from the highest degree 1 to the lowest 5 - which symbolises the pentatonic basic tone.

Singing according to the PIE pentatonic set of rules differs from those used in tonal music or in anhemitonic music. These rules have not yet been codified by researchers because the very Lükő Theory has only recently been "recovered". These pentatonic sets of rules govern the thinking of singers even though they visit the auxiliary tone $¥$. The presence of this does not have any effect on the inner logic of melody formation. It is also obvious that the addition of one more auxiliary tone does not necessarily affect pentatonic sets of rules. This can be seen in many medieval melodies preserved up to the present day. This auxiliary tone is inserted between the pentatonic degrees 5 and 4 and symbolised with the sign $\not \subset$. Functionally it may break down the feeling of pentatonic character in the tune. In other words, it destroys the pentatonic marker (3- 
4-5) and therefore it is called the Marker Annular by the present author. It corresponds to the 6th degree of major and minor. But, as said, the presence of the marker annular does not necessarily mean that the song is based on tonal logic. The melody may still be strongly anchored in the pentatonic logic. However, the fact is, that the marker annular only seldom occurs in the Krasnopol'skaja collection. If the marker annular is present in a melody, it theoretically makes the mode heptatonic. In spite of the actual number of tones in a tune, the mode with $\not \subset$ is always marked with the symbol 7. For instance, the mode $G^{1}-b^{1}-c^{2}-d^{2}-e^{2}$ flat $-g^{2}-a^{2}$ flat is symbolised by $g 7$ $I I I^{G L}$ even though the auxiliary tone $¥$ is missing between the degrees 1 ( $e^{2}$ flat $)$ and the upper octave of the basic tone $5\left(\mathrm{~g}^{2}\right)$, and the mode is hexatonic.

The modal structures in Table 1 are treated as "roots" by the present author because singers have rarely used them as such but picked varying numbers $(3,4,6,7$ etc.) of tone out of a certain root and constructed all kinds of modal structure. However, all transformations can be identified as belonging to the domain of one of these roots.

Along with György Kádár (1999), the present author supports Lükö's view that the songs of the Finno-Ugric populations were mainly based on anhemitonic structures. By anhemitonic is meant here the anhemitonic pentatonic modes of the type $d o, r e$, $m i$, sol and la. (If Do mode is $c-d-e-g-a-c$, then $L a$ mode is $a-c-d-e-g-a$ etc.) This view is opposed to the hypothesis of György Szomjas-Schiffert (1990, 202-210), supported by Yaxiong Du (1999, 301-317), according to which the anhemitonic modalities in Finno-Ugric traditions are of relatively recent Turkic influence. This hypothesis cannot fully explain the anhemitonic tradition in West Finland, not to speak of that in the Saame yoik in North Norway. However, the view of the anhemitonic background of Finno-Ugric singers still retains the status of a hypothesis.

\section{Analysis of the Transonegan Collection}

The Krasnopol'skaja edition has a varied collection of modal solutions. The singers naturally always had certain sets of musical rules in their minds. These rules do not have much to do with the tonal grammar or sets of rules. Instead, the singers had a surprisingly diverse supply of archaic modalities because of which the melodies elude efforts of analysis based on tonal interpretation. The Onegan peasants usually sang as one or two part choirs. Sometimes they maintained the same mode throughout the song. Sometimes the modal treatment led from one mode to another, or the singers transposed a mode by changing the position of the pentatonic basic tone. 


\section{A. The Indo-European layer of one-mode melodies}

The analysis is opened by identifying the melodies that are clearly of East-Slavic (< Proto-Slavic < Indo-European) origin and that stay in one mode from beginning to end. The 34 melodies in Table 2 represent all the six roots. Only one melody (no. 8 in Table 2) is completely pentatonic (PIE $I V^{\mathrm{GL}}$ ). It is a drawn-out song from Šun'ga (see Figure 3.A). The main part of one-mode melodies are with the additional tone $¥$, and especially the favoured root $I V^{\mathrm{GL}}$ also exists with the auxiliary tone $\not \subset$ or the marker annular. Lükö (1964) suggested that the Proto-Slavs had reformed their pentatonic structures to diatonic tetra-, penta- and hexachords. The present author has discovered the dominance of the same structures for instance in Lithuania, and presumed that these processes of transformation occurred during Neolithic times among the IE population who shared the more or less unified Central Indo-European or Balto-Slavic culture (Leisiö in print). The formation of three of them is illustrated in Figure 2.A.:

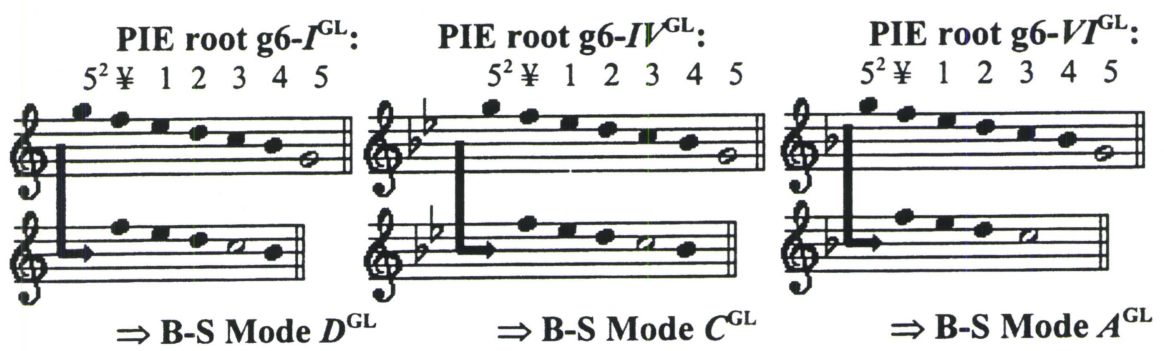

Figure 2.A. Proto-Indo-European pentatonic roots $I^{\mathrm{GL}}, I V^{\mathrm{GL}}$ and $V I^{\mathrm{GL}}$ with $g^{1}$ as the pentatonic basic tone also referred to by number 5 . The degrees are given in descending order. The roots are here in their hexachordic forms because of the auxiliary tone $¥$ between the degrees $5^{2}$ and 1 . The structures below the roots are their diatonic Balto-Slavic (B-S) derivatives avoiding the pentatonic basic tone 5 and defining the degree $3\left(c^{2}\right)$ as their new basic tone. The symbols $D, C$ and $A$ correspond to the symbols that Lükó (1964, 249-250 et passim) had originally used for his "altslawische Modi" (Proto-Slavic Modes).

In Table 2, items 1-5 represent the root $I^{\mathrm{GL}}$. Item 5 is its Balto-Slavic diatonic derivative $D$. Item 6 represents the root $I I^{\mathrm{GL}}$ (Figure 3.C), and item 7 is a beautiful example of the root III GL (Figure 3.D), so common in Scandinavian, Finnish and West-Karelian folk songs. The main part of melodies in Table 2 represent the PIE root $I V^{\mathrm{GL}}$. Items 12 , 13, 19 and 20 are its diatonic Slavo-Baltic derivatives $C$, and items 21-27 can be interpreted as the heptachordic forms of the PIE root $I V^{\mathrm{GL}}$. This interpretation rules out the possibility that the seven cases in question (21-27) represent the natural minor mode. The only one-mode melody in PIE root $V^{\mathrm{GL}}$ is item 28 . The rest of the melodies are based on the root $V I^{\mathrm{GL}}$ with item 31 as its Balto-Slavic diatonic derivative $A$. It can be seen that the general division of modal roots is roughly: $I V^{\mathrm{GL}}=60 \%, V I^{\mathrm{GL}}=17 \%$, $I^{\mathrm{GL}}=14 \%, I I=3 \%, I I I^{\mathrm{GL}}=3 \%$ and $V^{\mathrm{GL}}=3 \%$. 
It is not always clear when pentatonicism ends and tonality starts. As a good example is the melody in II-9a (no. 23 in Table 2: see Figure 3.B). The melody sounds close to West European popular tunes from the late Middle Ages. They also were heptatonic but not yet readily tonal by inner logic. The melody proceeds here in a way typical of late pentatonic logic in spite of the prominence of additional $a^{2}$ flat which is the annular of the pentatonic marker. On the other hand, the descending pentatonic marker 3$4-5\left(g^{1}-f^{1}-\underline{D}^{1}\right)$ is also clearly expressed. Because of the inner logic of the melodic progression, this song is interpreted as $d 7-I V^{\mathrm{GL}}$ and not as natural $G$ minor. And we may now understand that the melodic curve typical of Russian song, and associated with the "Slavic Sixth", is created here ascending from the 3rd pentatonic degree $\left(g^{1}\right)$ to the marker annular $e^{2}$ flat, descending then to the Basic Tone $d^{2}$ and back to the 3rd degree again. This is, however, only one solution to materialise this very Russian progression and emotion.

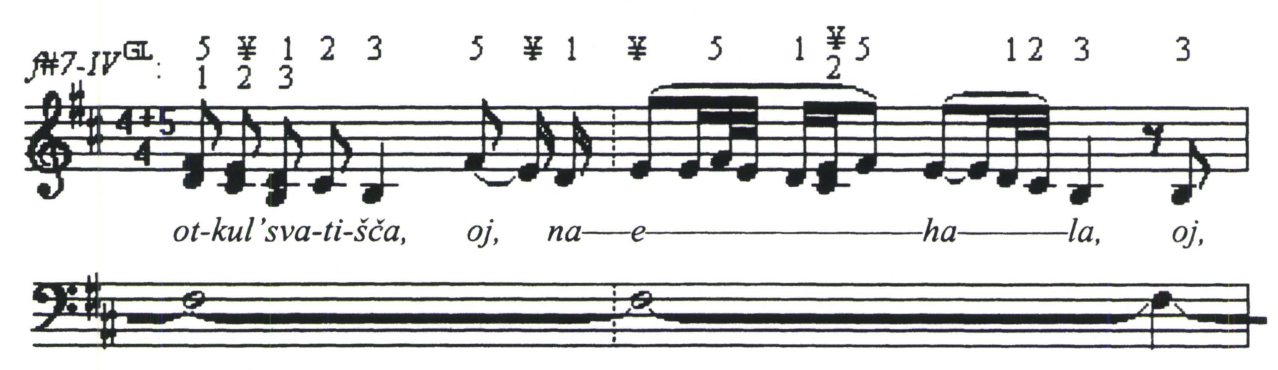

Figure 2.B. The melody of a farewell song with an imaginary drone marked beneath it.

Item 25 (Krasnopol'skaja III-36, pages 99-100) is a beautiful farewell song. It is not based on $B$ minor. Instead, the structure of melody is obviously based on the drone which is the pentatonic basic tone of the mode $f \# 7-I V G L$. The auxiliary tone $\not \subset=g 1$ appears once in each double line but this marker annular does not make the modality tonal. However, the feeling of the underlying $f \#$-drone is stronger than in most of the melodies in this collection. The imaginary drone is added below the 2 nd verse of stanza 1 in Figure 2.B.

It is possible to presume that this compositional technique represents an archaic ProtoSlavic tradition still met with in the Transonegan area. This interpretation forces the analyst to think again about the origins of Slavic folk polyphony. It may not be an accident that there are melodies in East-European folk traditions from Romania to Russia the structures of which are easily explainable by assuming the presence of a drone beneath the melody. 


\begin{tabular}{|c|c|c|c|c|c|c|c|c|}
\hline & \multirow[b]{2}{*}{ Root } & \multirow{2}{*}{$\begin{array}{l}\text { Basic } \\
\text { tone (5) }\end{array}$} & \multirow{2}{*}{$\begin{array}{l}\text { Initial } \\
\text { tone }\end{array}$} & \multirow{2}{*}{$\begin{array}{l}\text { Final } \\
\text { tone }\end{array}$} & \multicolumn{2}{|c|}{ Auxiliaries } & \multirow{2}{*}{$\begin{array}{l}\text { Numbers of } \\
\text { the collection }\end{array}$} & \multirow{2}{*}{$\begin{array}{l}\text { Modal } \\
\text { signum }\end{array}$} \\
\hline & & & & & $¥$ & $\not \subset$ & & \\
\hline 1. & $e \mathrm{~b} 6-I^{\mathrm{GL}}$ & $e^{1} \mathrm{~b}$ & 1 & $\left(5^{2}\right) 3$ & $d^{2} \mathrm{~b}$ & - & VI-72:IV & $6-I^{\mathrm{GL}}$ \\
\hline 2 & $f 6-I^{\mathrm{GL}}$ & $f^{1}$ & 1 & 3 & $e^{2} \mathrm{~b}$ & - & IV-44 & $6-I^{\mathrm{GL}}$ \\
\hline 3. & $f 6-I^{\mathrm{GL}}$ & $f^{1}$ & 3 & 3 & $e^{2} \mathrm{~b}$ & - & IV-45 & $6-I^{\mathrm{GL}}$ \\
\hline 4. & $f 6-I^{\mathrm{GL}}$ & $f^{1}$ & $3,2, ¥$ & 3 & $e^{2} \mathrm{~b}$ & - & VI-73:6 & $6-I^{\mathrm{GL}}$ \\
\hline 5. & $d 6-I^{\mathrm{GL}}$ & $d^{1}$ & (3)¥ & 3 & $c^{2}$ & - & $\mathrm{I}-8$ & B-S- $D$ \\
\hline 6. & $f 6-I I^{\mathrm{GL}}$ & $f$ & 1 & 5 & $e^{1}$ & & IV-63 & $6-I I G$ \\
\hline 7. & $f 6-I I I^{\mathrm{GL}}$ & $f$ & $5^{2}$ & 3 & $e^{1} \mathrm{~b}$ & - & VI-73:V & $6-I I I^{\mathrm{GL}}$ \\
\hline 8. & PIE $\boldsymbol{I} \boldsymbol{V}^{\mathrm{GL}}$ & $e^{1}$ & (1)3 & 5 & - & - & $\mathrm{I}-2$ & $I V^{\mathrm{GL}}$ \\
\hline 9. & $c 6-I V^{\mathrm{GL}}$ & $c^{1}$ & 2 & $2(3)$ & $b^{2} \mathrm{~b}$ & - & $\mathrm{I}-10$ & $6-I V^{\mathrm{GL}}$ \\
\hline 10. & $d 6-I V^{\mathrm{GL}}$ & $d^{1}$ & 4 & 4 & $c^{2}$ & - & IV-46 & $6-I V^{\mathrm{GL}}$ \\
\hline 11. & $d 6-I V^{\mathrm{GL}}$ & $d^{1}$ & (1)3 & 3 & $c^{2}$ & - & V-70 & $6-I V^{\mathrm{GL}}$ \\
\hline 12. & $d 6-I V^{\mathrm{GL}}>$ & $d^{1}$ & 3 & 4 & $c^{2}$ & - & IV-48 & B-S-C \\
\hline 13. & $d 6-I V^{\mathrm{GL}}>$ & $d^{1}$ & 4 & 2 & $c^{2}$ & - & IV-55 & B-S-C \\
\hline 14. & $e 6-I V^{\mathrm{GL}}$ & $e^{1}$ & 4 & 3 & $d^{2}$ & - & III-39 & $6-I V^{\mathrm{GL}}$ \\
\hline 15. & $f 6-I V^{\mathrm{GL}}$ & $f^{1}$ & (2)3 & 3 & $e^{2}$ & - & VI-73:5 & $6-I V^{\mathrm{GL}}$ \\
\hline 16. & $f \# 6-I V^{G L}$ & $f \#^{1}$ & (2)3 & 3 & $e^{2}$ & - & II- $4 \mathrm{a}$ & $6-I V^{\mathrm{GL}}$ \\
\hline 17. & $g 6-I V^{\mathrm{GL}}$ & $g$ & 3 & 3 & $f^{1}$ & - & V-68 & $6-I V^{\mathrm{GL}}$ \\
\hline 18. & $a 6-I V^{\mathrm{GL}}$ & $a^{1}$ & (5)3 & 3 & $g^{2}$ & - & $\mathrm{I}-13$ & $6-I V^{\mathrm{GL}}$ \\
\hline 19. & $b 6-I V^{\mathrm{GL}}>$ & $b^{l}$ & 4 & 3 & $a^{2}$ & - & III-41 & B-S-C \\
\hline 20. & $b 6-I V^{\mathrm{GL}}>$ & $b$ & 3 & 4 & $a^{1}$ & - & V-69 & B-S-C \\
\hline 21. & $c 7-I V^{\mathrm{GL}}>$ & $c^{1}$ & $5(¥)$ & 3 & $b^{1} \mathrm{~b}$ & $d^{2}$ & $\mathrm{I}-18$ & $7-I V^{\mathrm{GL}}$ \\
\hline 22 . & $d 7-I V^{\mathrm{GL}}$ & $d^{1}$ & $5^{2}$ & $5^{2}$ & $c^{2}$ & $e^{2} \mathrm{~b}$ & V-67 & $7-I V^{\mathrm{GL}}$ \\
\hline 23. & $d 7-I V^{\mathrm{GL}}$ & $d^{1}$ & $5^{2}$ & 3 & $c^{2}$ & $e^{2} \mathrm{~b}$ & II-9a & $7-I V^{\mathrm{GL}}$ \\
\hline 24. & $f 7-I V^{\mathrm{GL}}$ & $f^{1}$ & 3 & 3 & $e^{2} \mathrm{~b}$ & $\mathrm{~g}^{2}(\mathrm{~b})$ & $\mathrm{I}-23$ & $7-I V^{\mathrm{GL}}$ \\
\hline 25. & $f \# 7-I V^{G L}$ & $f \#^{1}$ & 5 & 3 & $e^{1}$ & $\mathrm{~g}^{1}$ & III-36 & $7-I V^{\mathrm{GL}}$ \\
\hline 26. & $f \# 7-I V^{\mathrm{GL}}$ & $f \#^{1}$ & & 5 & $e^{1}$ & $\mathrm{~g}^{1}$ & III-37 & $7-I V^{\mathrm{GL}}$ \\
\hline 27. & $g 7-I V^{\mathrm{GL}}$ & $g^{1}$ & 3 & (5)3 & $f^{2}$ & $a^{2} \mathrm{~b}$ & II- $25 b$ & $7-I V^{\mathrm{GL}}$ \\
\hline 28. & $d 6-V^{\mathrm{GL}}$ & $d^{1}$ & 3 & 3 & $c^{2}$ & - & $\mathrm{I}-7$ & $6-V^{\mathrm{GL}}$ \\
\hline 29. & $c 6-V I^{\mathrm{GL}}$ & $c^{1}$ & 3 & 1 & $b^{1} \mathrm{~b}$ & - & IV-55 & 6-VIGL \\
\hline 30. & $d 6-V I^{\mathrm{GL}}$ & $d^{1}$ & (2)3 & 3 & $c^{2}$ & - & I-1; II-1a & $6-V I^{\mathrm{GL}}$ \\
\hline 31. & $e 6-V I^{\mathrm{GL}}$ & $e^{1}$ & 3 & 3 & $d^{2}$ & - & $\mathrm{I}-28$ & 6-VIGL \\
\hline 32. & $f 6-V I^{\mathrm{GL}}$ & $f$ & $1(5)$ & 5 & $e^{1} \mathrm{~b}$ & IV-61 & $6-V I^{\mathrm{GL}}$ & \\
\hline 33. & $f 6-V I^{\mathrm{GL}}$ & $f$ & 3 & 3 & $e \mathrm{~b}^{1}$ & IV-43 & $6-V I^{\mathrm{GL}}$ & \\
\hline 34. & $f 7-V I^{\mathrm{GL}}$ & $f^{1}$ & 3 & 3 & $e \mathrm{~b}^{2}$ & $g^{2}$ & VI-73:I & $7-V I^{\mathrm{GL}}$ \\
\hline
\end{tabular}

Table 2. The Transonegan melodies based on one INDO-EUROPEAN pentatonic root only, and arranged according to the Lükö Theory. 
A:

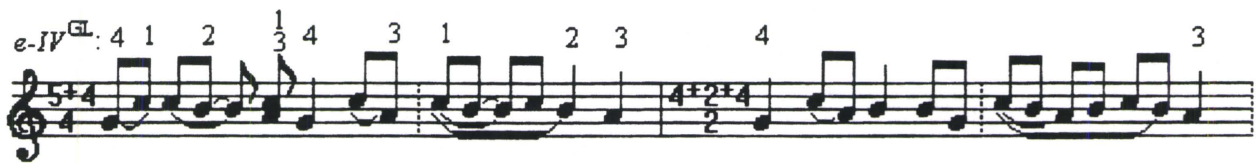

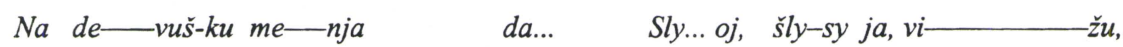

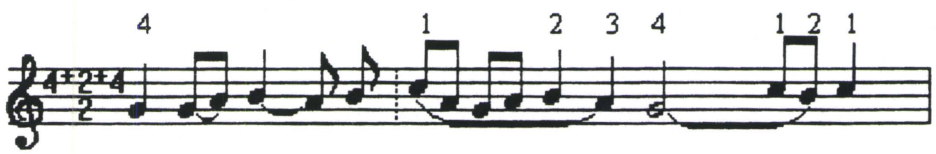

$d e-v u s ̌ k a, \quad d o-s a-d u s-k u$

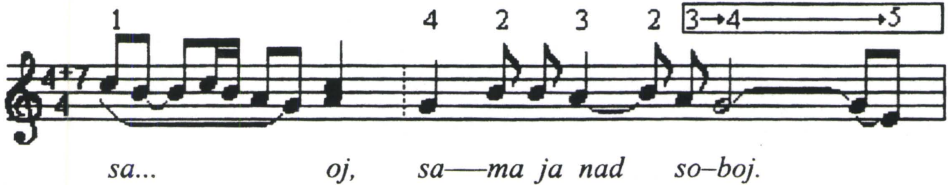

sa...

oj, $\quad$ sa-ma ja nad $\quad$ so-boj.

B:

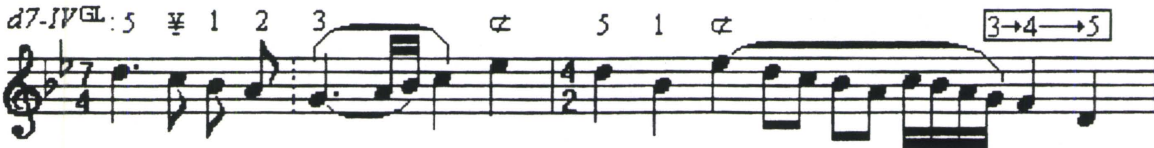

Vro-šči-ce o-din da, Stal vy-spra— $\quad$ ši-vat'

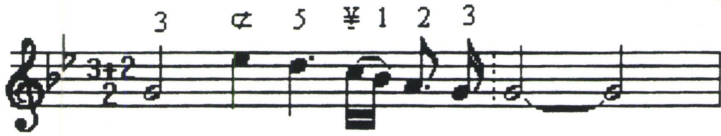

u... ah, u svo-ej mi-loj.

C:

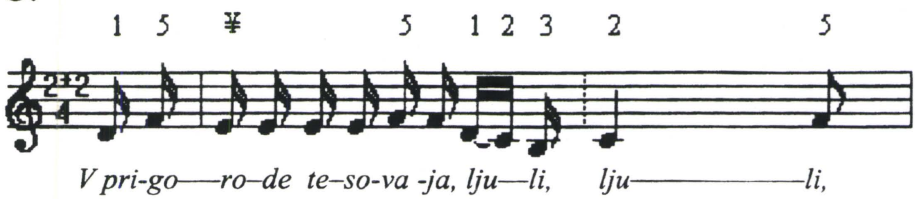

D:
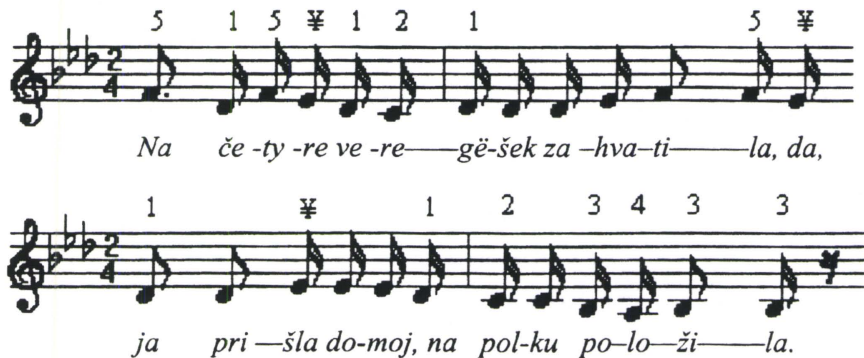

Figure 3.A. The 3rd stanza of the pentatonic drawn-out song in $d-I V^{\mathrm{GL}}$ from Sun'ga (Krasnopol'skaja 1987, no. I-2; page 23; recorded in 1976). The song is closed by the pentatonic marker 3-4-5 with the pentatonic basic tone as the finale. -3 .B. A drawn-out song in $d 7-I V^{\text {GL }}$ sung by V. D. Lysanov in 1916 according to what he remembered having heard in 1886 in his home village of Sennaja Gubá. (Krasnopol'skaja 1987, no. II-9a; page 83). The pentatonic marker functions as an intermediary cadenza. -3 .C The 2 nd verse of a ritual song of praise from item 6 in Table 2 (Krasnopol'skaja 1987, IV-63,page 120). The root is f6-II ${ }^{\mathrm{GL}}$. The pentatonic basic tone functions as the finale, and the auxiliary tone $¥$ is $e^{1}$. The mode may be of Proto-Slavic origin.3.D. The second stanza of a youth song from item 7 in Table 2 (Krasnopol'skaja 1987, V-73:V, pages 139140 ). The root is $f 6-I I I I^{\mathrm{GL}}$ with the pentatonic basic tone as the initial tone and the 3rd degree as the finale. The closing formula 3-4-3 is quite common to this root. 
Another kind of a technique appears in item 26 (Krasnopol'skaja III-37, pages 100_ 101). It is a two-part farewell song. The melody only looks like a $B$ minor tune but is a typical Indo-European pentatonic composition. However, the arrangement of the two parts is interesting. In the stanzas 1 and 2 of this melody, the upper part is based on $b-I V^{\mathrm{GL}}$ while the lower part moves strictly in f\#6-IVGL:

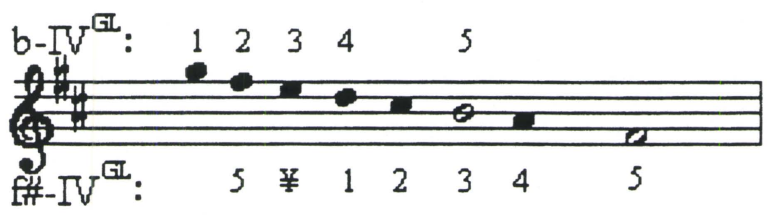

The two modal layers are intertwined but clearly separate until both voices unite in the 3rd stanza in which the melody moves solely in $f \# 6-I V^{\mathrm{GL}}$ having its 3 rd degree $b$ (= also the basic tone of $b-I V^{\mathrm{GL}}$ ) as the finale. This kind of technique is well suited to Indo-European modal systems but it seems that it was mainly typical of East-Slavic singers. Anyway, the principle of forming modally layered melodies differs a lot from the previous drone-based one but the two seem to spring from the same archaic tradition of melody formation.

The modal root $V I^{\mathrm{GL}}$ is found in songs of praise for weddings. Among them item 29, Ne jahotnik po gornice katalsja (Krasnopol'skaja IV-55, page 117), is exceptional because of its structure. It is identifiable as $c 6-V I^{\mathrm{GL}}$ with the basic tone $c^{2}$ as the highest one and the 1 st degree $a^{1}$ as the finale. If this interpretation is correct, the style of the tune turns out to be quite old. The younger a melody, the more probable it is that the finale will be the 3rd degree. There are elements in this melody (such as the cadential formula) which can be found e.g. in old Germanic and Lithuanian melodies. We may compare the cadences in this Transonegan song and a German legend (Habenicht 1977 , no. 28) $)^{2}$ obeying the same root $c 6-V I^{\mathrm{GL}}$ :

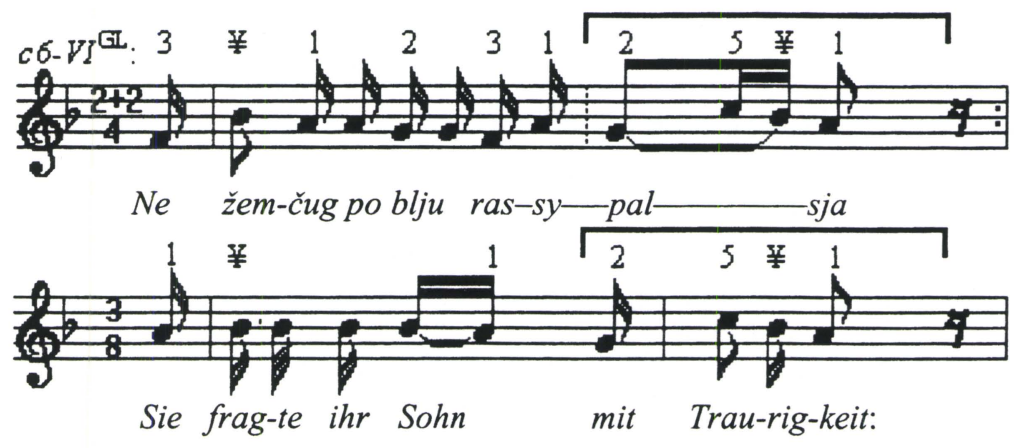

2 The song is a medieval Easter legend Als Jesus von seiner Mutter ging from Roman Catholic SouthGermany but also widely known in German speaking diaspora traditions in East Europe. This variant was tape recorded in Romania. 
It is quite possible that this iterative wedding song type goes back to Proto-Slavic rituals. It is not quite certain whether the modality of item 33 is $f 6-V I^{\mathrm{GL}}$, too, because the 4th degree ( $a^{1}$ flat or $a^{1}$ ) is missing (see Figure 3.C). The melody moves in a way typical of the root $V I^{\mathrm{GL}}$, though, and therefore the root $f 6-I^{\mathrm{GL}}$ is not probable. The point is that the melody type of this ritual song circulates between degrees 3,1 and 5 of the pentatonic root.

As a good example of the sixth PIE root is item 32 in Table 2 (Krasnopol'skaja no. I: 28, pages 73-75). The melody proceeds as if in $e^{1} 6-V I^{\mathrm{GL}}$ but the singers avoid the 4 th pentatonic degree until the very end of each stanza which can be seen in Figure 4.A. Fortunately they also visit the 4th degree at the beginning of the third stanza (Vo sle-za...) which supports the absolute identification of the present modality. In other words: the singers themselves were totally aware of the exact position of the 4th pentatonic degree.

A:

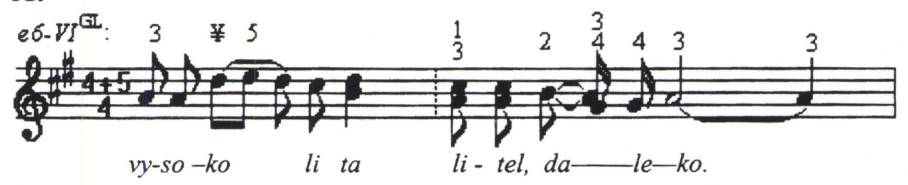

B:
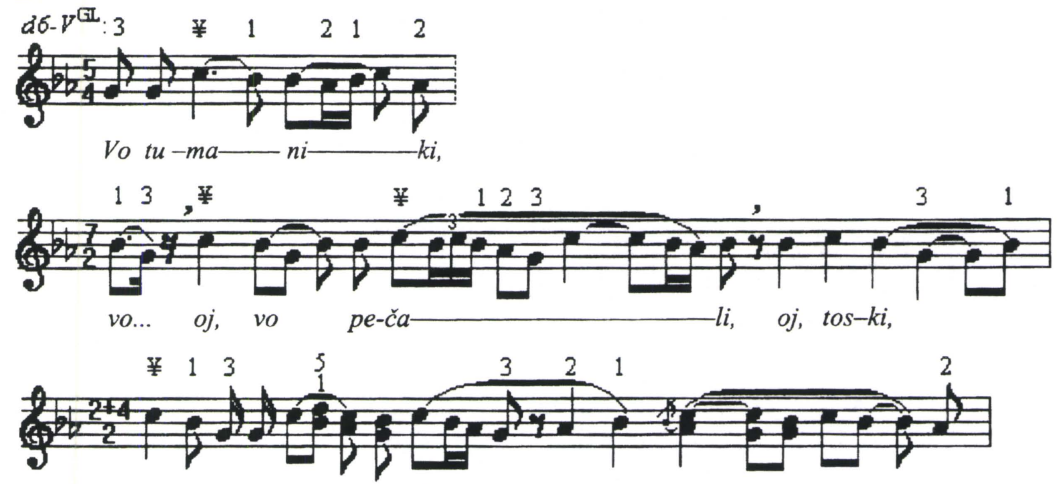

Oj, si-žu ja, kras-na de$k a$,
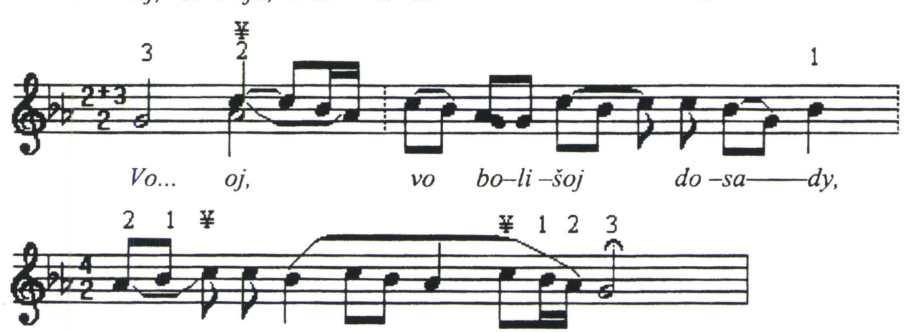

Vo

do-sa $\mathrm{s} \longrightarrow$.

Figure 4.A. The closing formula of the first stanza of a drawn-out melody as a simplified presentation of Krasnopol'skaja 1987, no. I-28 (pages 73-74). The melody is based on $e^{1} 6-V I^{\mathrm{GL}}$. The 4th degree $\left(g^{1}\right)$ does not appear except as the leading tone to the finale $a^{1}$, and the basic tone occurs only as its upper octave $e^{2}$. The style is profoundly Russian. - 4.B. The first stanza of a drawn-out melody as a simplified presentation of Krasnopol'skaja 1987, no. I-7 (pages 32-35). The melody is based on the root $g^{1} 6-V^{\text {GL }}$. The basic tone $g$ only crops up in the first stanza on the third line as $g^{2}$. 


\section{A critical commentary}

The melodies are transcribed according to the views coined by the influential Soviet musicologist Evgenij Gippius who had recorded many of the original phonograms in 1926, transcribed them and also supervised the editorial work on the rest of the melodies published (Krasnopol'skaja 1987, 6-9 et passim). The tunes look very complex and, for an outsider like the present author, it is difficult to grasp how the singers could produce such melodies like the drawn-out songs varying from stanza to stanza. Therefore it was more than valuable that the author had an opportunity to visit the Puškin House Archive in St. Petersburg and to listen to some of the original phonograms.

THE PUBLISHED INTERPRETATION: $(\bullet=80)$

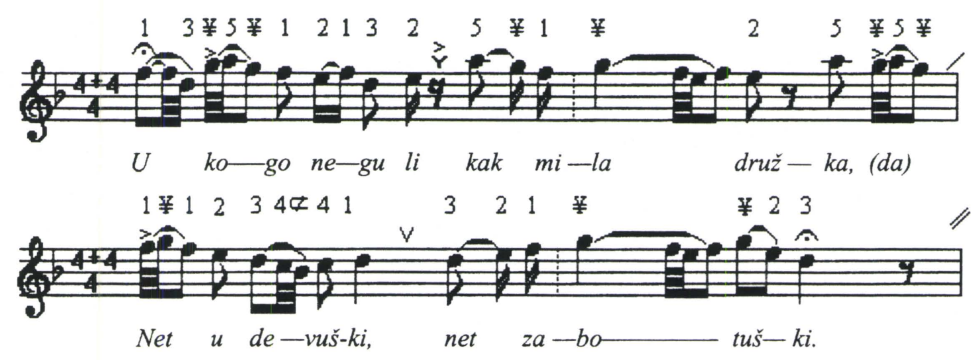

THE REVISED INTERPRETATION:

2nd:

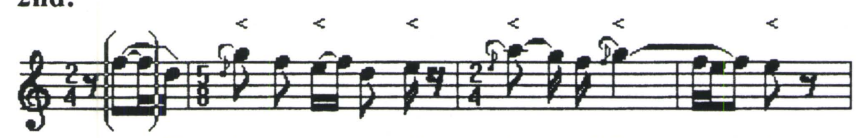

U ko-go ne-tu li kak mi-la dru-

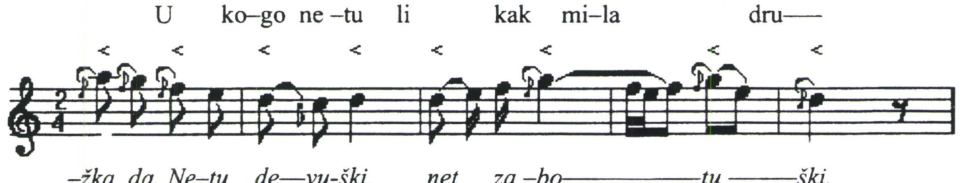

4th:

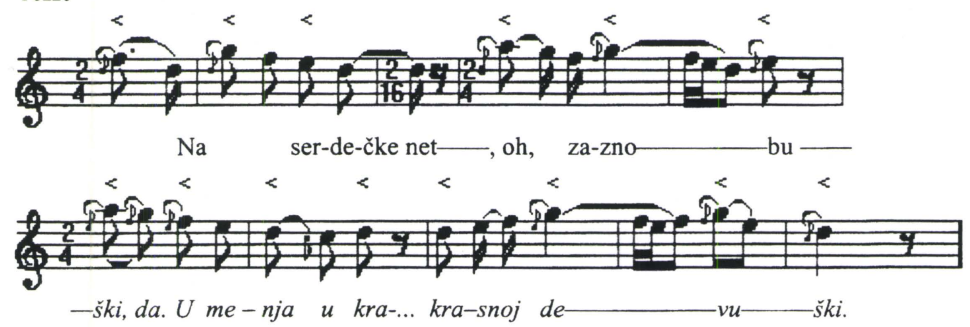

Figure 5. This slow drawn-out song was sung in the highest possible register by a woman in the village of Botvišcina in 1926. The second stanza originally transcribed by E. V. Gippius. (After Krasnopol'skaja 1987, I-13; pages 49-50.) The PIE mode is $a^{1} 6-I V^{\mathrm{GL}}$. Below is the same stanza (2nd) followed by the fourth stanza (4th) according to the interpretation of the present author. (The source: The Sound Archive of the Puškin House, tape 33DM 1528, no 32-0048.) 
The present author cannot always agree with the results reached through Gippius' method of transcription. There is no doubt that transcriptions may vary depending on the transcriber. As an example of disagreement I here submit item I-13 which is first given as it is printed and then as a revised version in Figure 5.

If interpreted according to the revised manner, it is easy to understand that the singer had a solid formal structure in her mind. Whichever ways she varied the melody, all the stanzas are logically related to the basic pattern of four melodic hemistichs [puolisäe in Finnish]. The melody is most probably a variant of some medieval popular tune from Central Europe closely related to the 17th century Lutheran chorale style in Scandinavia and Finland. It seems therefore that at least some of the curious drawn-out melodies are less problematic by inner logic as it seems at first sight.

As seen in stanzas 2 and 4, the end of the first melodic double line is not the end of the textual double line but its last syllable starts the second melody line added by an auxiliary word $d a$ 'yes' - as seen in the juncture of the two verses A and B of the second stanza inside the box nearby.

A: $\quad$ B:

Melodic verses:

Textual verses: --- kak mila dru—— žka, da. Netu devuški---

The published transcription is written as if in $d$ minor which explains the presence of $b$ flat. The singer does not, however, visit that tone - not even in the second stanza, contrary to the view of Professor Gippius. The mode is not minor but a hexachord based on the PIE root $a^{1}-I V^{\mathrm{GL}}$. Being late pentatonic by character ( $\left.¥=g^{2}\right)$, tone $b^{1}$ flat does not suit this melody very well. If sung out, it had the function of the annular $\not \subset$ of

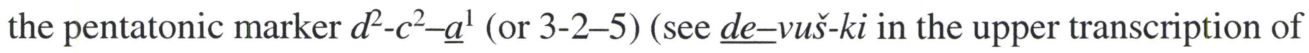
Figure 5). Because of the total absence of this tone there are no accidentals in the interpretation of the present author in Figure 5. The singer systematically punctuated every second quarter-note and so she obviously materialised a meter in her mind which can be defined mainly as $2 / 4$. That is why this meter is added to the new interpretation. 

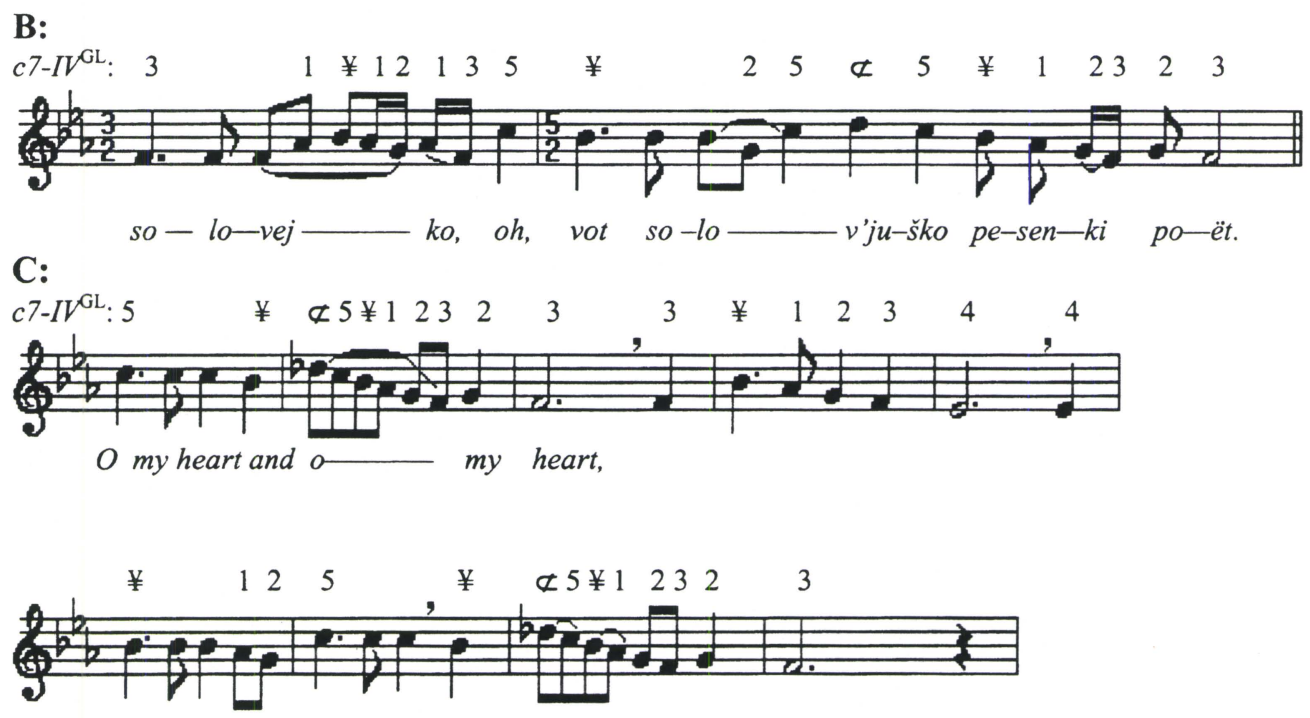

Figure 5.B. The melodic nucleus of the drawn-out song $U$ moëgo-to bylo u milogo after Krasnopol'skaja 1987, I-18 (pages 57-59). The tune proceeds in a way typical of West European popular tunes in $c$ based root $I V^{\mathrm{GL}}$. Characteristic of these melodies is a prominent marker annular $\ddot{\mathrm{E}}$ which is here inserted in the position of maximum stress in the word so-lo-v'júšs-ko 'little nightingale'. $-C$. An English melody $O$ My Heart based on Proto-Germanic pentatonic tradition. It was composed by King Henry 8th (1491-1547). It starts from the pentatonic basic tone 5 and ends up on the 3rd degree of the mode $c 7-I V^{\mathrm{GL}}$. The marker annular has a prominent function. (The transcription of the author according to MMAR, Side 1, Band 1b.)

It seems quite obvious that there is a possibility of identifying a layer in medieval style from Western Europe in the Transonegan repertoire. In Figure 5.B the drawn-out song $U$ moёgo-to bylo u milogo represents a melody typical of late medieval popular tunes of the time of the troubadours. The modal root is $c-I V^{\mathrm{GL}}$. From the point of view of music history this tune goes back to a situation when late pentatonic hexachords started to expand to late pentatonic heptachords. The modal structures were not related to church modes. Neither were they tonal, yet. They were inbetween pentatonicism and tonality. That is exactly what characterises this tune as having a very strong marker annular $\not \subset=d^{2}$. Because of this the symbol of this mode is $c^{1} 7-I V^{\mathrm{GL}}$. An example of a typical English melody in the same late pentatonic mode is given in Fig. 5.C. This tune was composed as late as the early 16th century but the style is much older. In the Middle Ages the marker annular (which was later to become the tonal 6th degree) usually had a vague character because of which it was sometimes $d^{2}$ (like in Fig. 5.B) and sometimes $d^{2}$ flat (like in Fig. 5.C). 


\section{B. Indo-European layer of melodies with modulation and transposition}

It has been typical of Indo-European singers either to transpose a mode to another position during a song, or to modulate from one root to another. The Transonegan singers also knew both techniques.

\section{B.1. Cases of Modulation}

According to the prevailing interpretation in musicology, a folk melody is normally thought to materialise one certain mode from the beginning to end. This seems, however, to be a false point of departure in the analysis of modalities. The Lükö Theory forces the researcher into new kinds of interpretation to grasp what was going on in the minds of singers. It seems more than obvious that the modulation techniques in western art music are nothing but a continuation of a millennia-long practice cleverly used by singers who identified themselves as the bearers of Indo-European cultures. Gábor Lükő encountered this techniques when studying the melodies of NorthwestRussian bylinas. In spite of that, he did not realise how customary it was for European folk singers to use vivid modulation. In other words, it is far from easy to get rid of the classical zero hypothesis according to which melodies anywhere beyond the western art music are naturally based on one mode only.
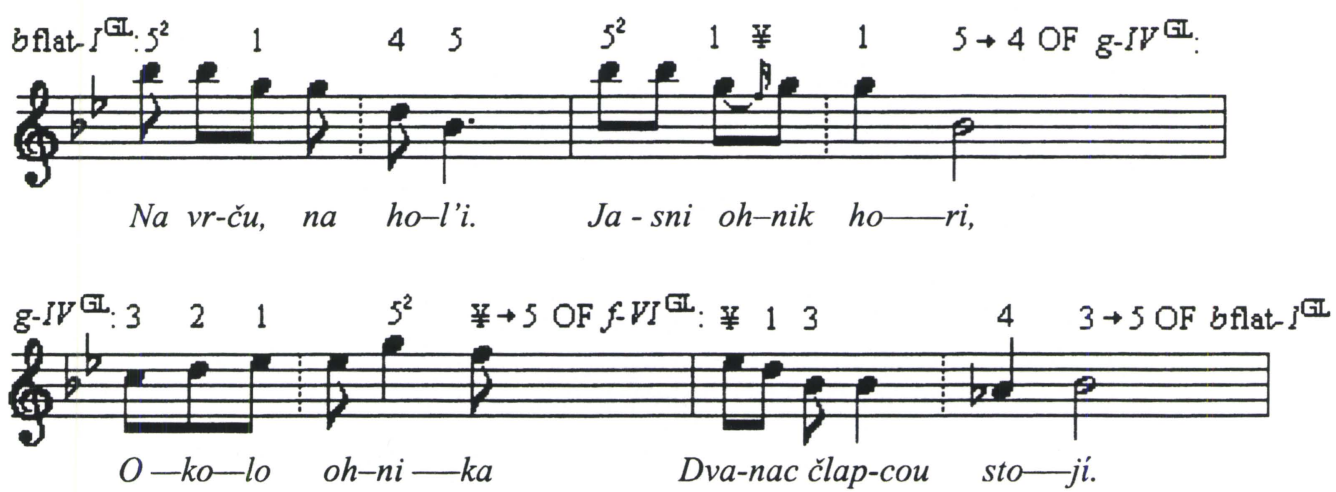

Figure 6. A perfectly constructed chain of modulations from Slovakia according to an archaic IndoEuropean descending pentatonic tradition (Lükö 1964, mode type XXVII-1). The song starts in root $I^{\mathrm{GL}}$ in $b$ flat. The line ends at its pentatonic basic tone $b$ flat which also is the 4 th degree of the root $g$ $I V^{\mathrm{GL}}$. The second line starts as an ascending progression till it reaches the basic tone $g^{2}=5^{2}$. The textual hemistich ends at the auxiliary tone $f^{2}$, which is also the basic tone 5 of the third root, $g$ - $V I^{\mathrm{GL}}$. The song is closed with the 3 rd degree $b$ flat of this root which is also the basic tone of the initial root (and the beginning of the next stanza). The song is a nicely put circle with each of the three sections having a specific mood of its own. 
As an example is the Slovakian highway robbers' song in Figure 6. According to professor Lükö, the mode is the root $I V$ in $g$ with $f^{2}$ and $a^{1}$ flat as the auxiliary tones, and with $b$ flat as the initial and final tone (Lükö 1964, 272-276 and "Typus" XVII:1). More obviously, however, the tune is composed of the chain of three modes in a sequence of $1 / 2 b$ flat- $I^{\mathrm{GL}} \Rightarrow g-I^{\mathrm{GL}} \Rightarrow f-V I^{\mathrm{GL}} \Rightarrow^{1 / 2} / 2$ flat- $I^{\mathrm{GL}}$ etc. The melody has too many regularities to be but accidentals. E.g. the 4 th degree functions as a leading tone to the Pentatonic basic tone $(4 \Rightarrow 5)$ or to the 3 rd degree. In European traditions the modulations often occur by choosing a new finale upon a fourth or a fifth from the previous one. Accidental or not, in this case the Pentatonic basic tones correspond to the degrees $b$ flat-Do, $f$-Sol and g-La of hemitonic systems.

Songs can be found with at least one modulation in the Transonegan tradition. These kinds of song usually belong to archaic contexts of culture, but not necessarily. As an example of quite recent repertoire are the quadrille dance songs. One of them, $V e j k a$, vejka, veteroček (Figure 7), modulates from $f-I^{\mathrm{GL}}$ to $c 6-I V^{\mathrm{GL}}$ in quite a fascinating way which is certainly not tonal.
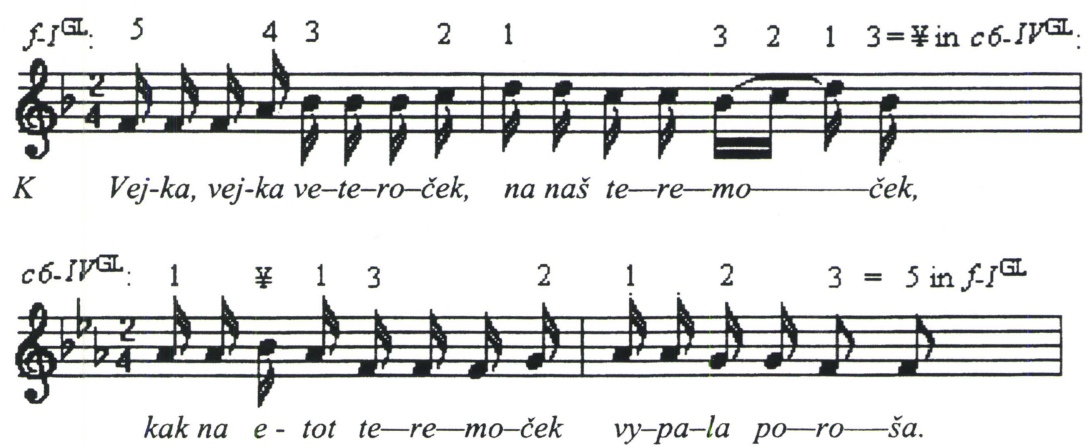

Figure 7. This quadrille is a nice interplay of the major resembling mode $f-I^{\mathrm{GL}}$ and minor resembling mode $c-I V^{\mathrm{GL}}$. The finale of the melody is the Pentatonic basic tone (5) of the beginning stanza. After Krasnopol'skaja 1987, VI-73:III (page 137).

It is not always easy to judge whether there is a deliberate modulation in a melody. A visit to another mode also may be an accident or a mistake when singing. As an example is a lyrical drawn-out song $U$ menja kak bylo u mladëšen'koj bylo dva gorja 'Young as I am, I have two sorrows' (Figure 8) which was one of the most popular in European Russia. Modally it represents a typical Balto-Slavic type of a melody formation, and this Transonegan variant obeys the root $g \# 6-I V^{\mathrm{GL}}$ through the descending mode $g^{1} \#-f^{1} \#-e^{1}-d^{1} \#-c^{1} \#-b$ (corresponding to the degrees 5-¥-1-2-3-4 of root $I V^{\mathrm{GL}}$ ). The solo singer opening the performance also visited tone $d^{1}$ instead of $d \#^{1}$ at the end of the first line. In this context $d^{1}$ has the function of the 2nd degree of root $g \#-V^{G L}$. The singer may or may not have made a mistake but this short visit seems to support the suggestion made above that the locals knew the PIE root $V^{\mathrm{GL}}$. -To repeat, otherwise the melody is based purely on the root $g \# 6-I V^{\mathrm{GL}}$. 


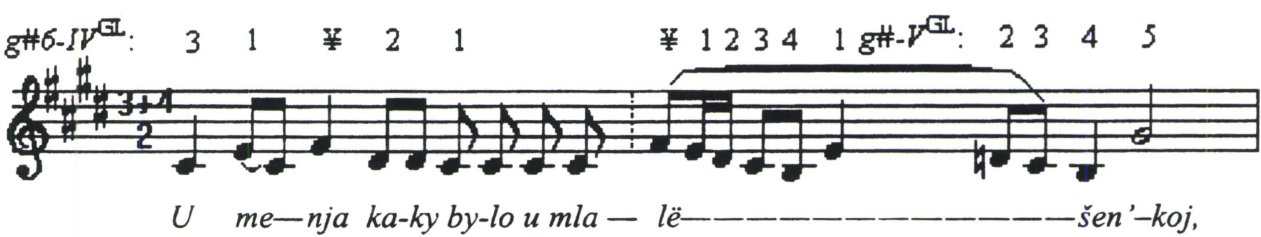

Figure 8. The first verse of a drawn-out song in Krasnopol'skaja 1987, I-15 (pages 52-53) modulates from $g \#-I V^{\mathrm{GL}}$ to $g \#-V^{\mathrm{GL}}$ after the tone $e^{1}$ in syllable -lë-. The melodic line ends at the Pentatonic basic tone 5 of both roots. At the end of the line the sequence 3-4-5 is the pentatonic marker in a reversed direction, that is, instead of tone $g \#$ the performers sing its upper octave $g \#^{1}$. In the 2 nd verse they modulate right back to $g \#-I V^{\mathrm{GL}}$ which is the modal root for the rest of the performance. The melody was tape recorded in Šun'ga in 1976.

The wedding song III-35 (Figure 9) is constructed so that the two first verses go in $d 6$ $V I^{\mathrm{GL}}$, the second verse modulates to $e 6-I V^{\mathrm{GL}}$ which transposes a fifth downwards to $a 6-I V^{\mathrm{GL}}$ and finally modulates back to the initial $d 6-V I^{\mathrm{GL}}$. To help the reader, each of the three modes in Figure 9 are first presented as scales. The actual tones in function are inside the boxes:

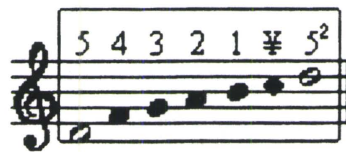

$d^{1} 6-V T^{\mathrm{GL}}$
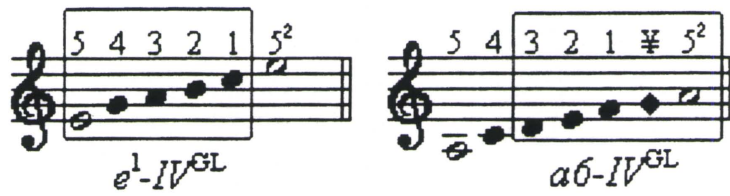

It is not necessary to assume any modulation to $e 6-I V^{\mathrm{GL}}$. It may be enough to say that the singers modulated directly from $d-V I^{\mathrm{GL}}$ to $a 6-I V^{\mathrm{GL}}$ which means that the melody is a continuous interplay of $d-V I^{\mathrm{GL}}$ and $a-I V^{\mathrm{GL}}$. In spite of this, the example in Figure 9 is offered with the modulation to $e 6-I V^{\mathrm{GL}}$ as well. On the second line the modulation occurs twice so that the 3 rd degree of the presiding mode changes to the 5 th degree (= basic tone) of the beginning mode.
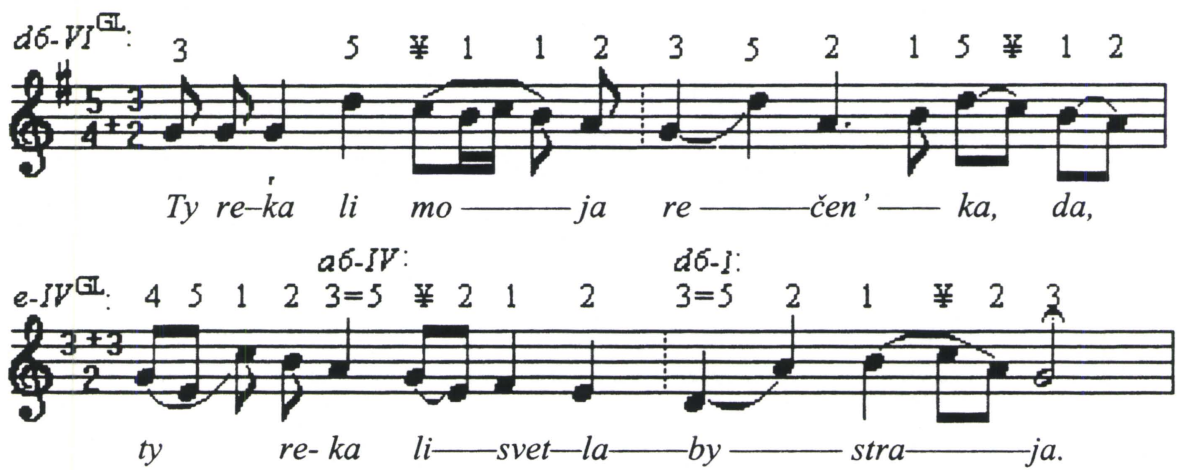

Figure 9. The modulations in a wedding song after Krasnopol'skaja 1987, III-35 (page 98). The first change of "key" occurs at the end of the upper line $\left(d a\right.$, ) where the degrees 1 and 2 of the active mode $V I^{\mathrm{GL}}$ are also degrees 2 and 3 of the following $e$-based mode $I V^{\mathrm{GL}}$. Other points of modulation are by the corresponding transformations of degree function " $3=5$ ", that is, during the syllables $-k a$ and $-b y$ - on line 2 . 
The drawn-out melody no. I-9 (Figure 10.A) is complex in structure. The main mode is clearly the hexachordic $d^{1} 6-V^{\mathrm{GL}}$ :

$$
\begin{aligned}
& 5^{2}-¥-\quad 1-\quad 2-\quad 3-4-5 \\
& d^{2}-c^{2}-b^{1} \text { flat }-a^{1} \text { flat }-g^{1}-f^{1}-\underline{D}^{1} \text {. }
\end{aligned}
$$

However, the singers did not start the melody (Pripozydal) in that mode but in a major-like full pentatonic $e^{1}$ flat- $I^{\mathrm{GL}}$, that is, a mode having its basic tone a half step higher:

$$
\begin{aligned}
& \text { 1- 2- 3- } 4-5 \\
& c^{2}-\quad b^{1} \text { flat - } a^{1} \text { flat }-g^{1}-\quad \underline{E}^{1} \text { flat. }
\end{aligned}
$$

This kind of solution is quite rare because of the relation of a half second between the two basic tones. The author has no other option but to state that this is the structure however strange it may look. On the other hand, the melody moves logically according to this interpretation. The final cadence ( $d v o . . ., d v o e$, ne odin) is frequently met with in Germanic folk songs in this very same root. Perhaps some elements common in Middle Europe are not of late German influence in Transonegan culture. More probable is that some stylistic elements in this song go back to an ancient tradition already known by Proto-Slavic singers. This is purely a guess. This possibility must however be taken seriously and borne in mind. It will require more evidence to confirm it.

Item III-31 is a ritual farewell song from weddings (Figure 10.B). It resembles the items III-32, 33 and 34 sharing the same ritual function but these three are clearly dominated by Sol pentatonic modality (see Figure 19.C). The version in Fig.10.B radically differs from these three because of its modal composition. Simple as it looks, it is based on the chain of three modulations. The basic tones of the three successive PIE modalities follow the descending order of natural tones nos. 5, 4 and 3 (or the major triad). How to explain this? The author has no answer but this melody seems to represent a very archaic Indo-European modal thinking characterised by modulation. In this case the chain of pentatonic basic tones is $f \#^{1}-d^{1}-a$ and the modal roots based on them are $f \#^{1}-V^{\mathrm{GL}}, d^{1}-I^{\mathrm{GL}}$ and $a-V I^{\mathrm{GL}}$. If this interpretation is accepted the tune appears logical to the very end and is easy to learn. If we try to offer any other explanation to the logic in the melody formation, the underlying musical grammar is quite difficult to grasp. 
A:
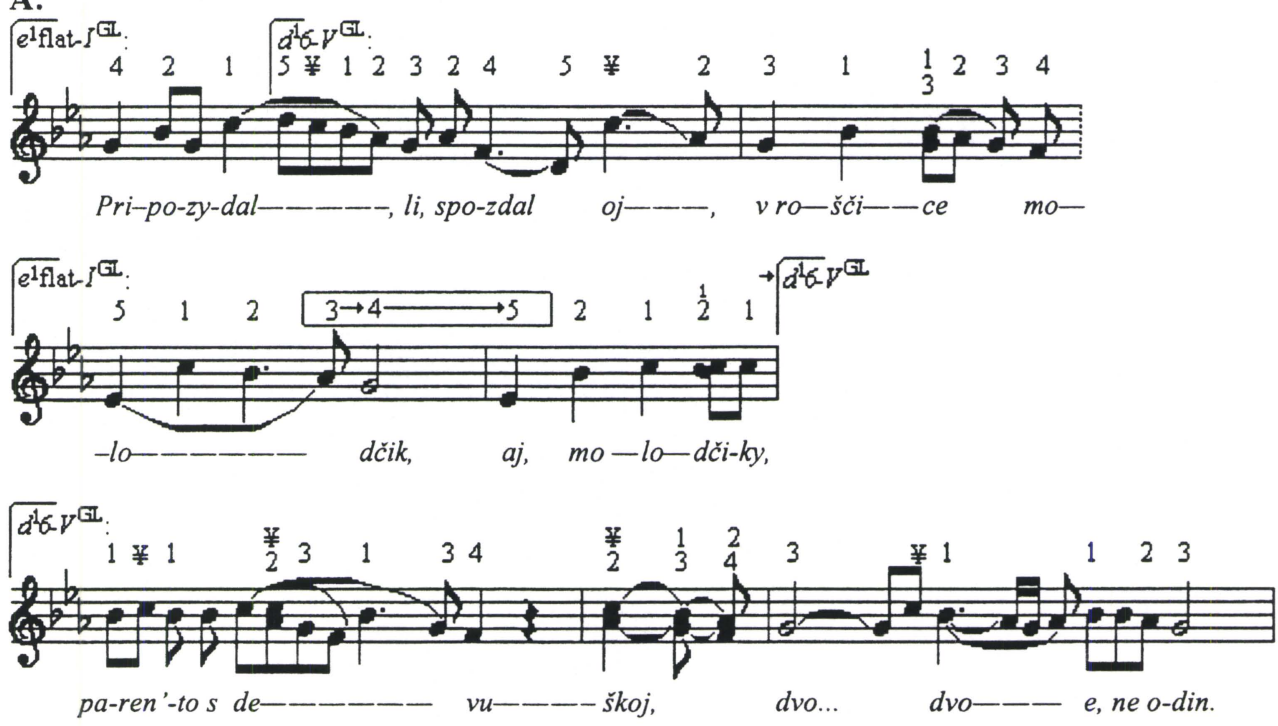

B:
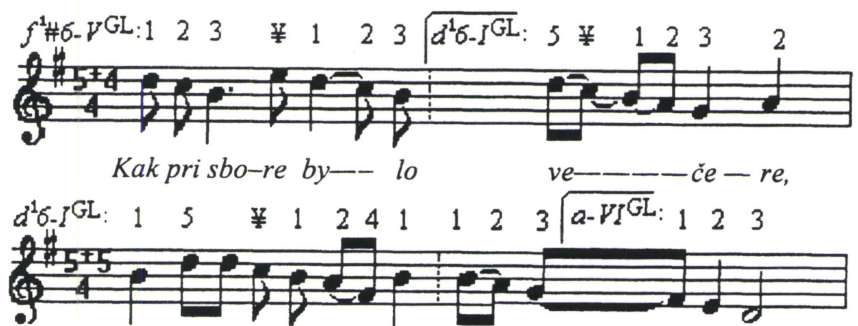

pri to-i pozd-noj ve- že- ri- noč-ki.

Figure 10.A The first stanza of a drawn-out song Pripozdal li, spozdal $v$ rotcice molodcik 'Was the young lad late in the forest?' after Krasnopol'skaja 1987, I-9 (pages 38-40). The main mode is $d 6$ - VGL but it also modulates to $e$ flat- $I^{\mathrm{GL}}$. -10 .B. A bride's farewell song after Krasnopol'skaja 1987, III-31 (page 93). The melody starts in f\#-based root $V^{\mathrm{GL}}$ ending on its 3rd degree. Then the singers modulated to the $d$-based root $I^{\mathrm{GL}}$. This section ends in the last bar through the cadence of 1-2-3 after which the melody modulates one more time to the root $a-V I^{\mathrm{GL}}$. The melody ends again via the cadence of 1-2-3 and the finale is the same as the first degree of root $V^{\mathrm{GL}}$ which restarts the song as its upper octave. The melody is cleverly constructed. Did the singers really modulate from $d-I^{\mathrm{GL}}$ to $a-V I^{\mathrm{GL}}$ ? What if they simply transposed $d-I^{\mathrm{GL}}$ to $a-I^{\mathrm{GL}}$ ? The question is not material, actually, but because the tone $c$ has a function in the previous sections of the song, it is safe enough to presume that $a-V I^{\mathrm{GL}}$ was actually in the minds of the singers when modulating to $a$-based mode. Tone $c$ is the 4th degree of $a$-VI $I^{\mathrm{GL}}$.

The drawn-out melodies sometimes vary a great deal. An interesting feature, also common to South Caucasian polyphony, is the avoidance of repetition. As a good example is Hot'-to rabotlivoë (Figure 11). Even if a choral song, the texture changes all the time during the five stanzas. From the modal point of view, the governing mode is $e 6-I V^{\mathrm{GL}}$ and all the stanzas are closed with a formula in $e 6-V^{\mathrm{GL}}$ as happens at the end of the second stanza: 


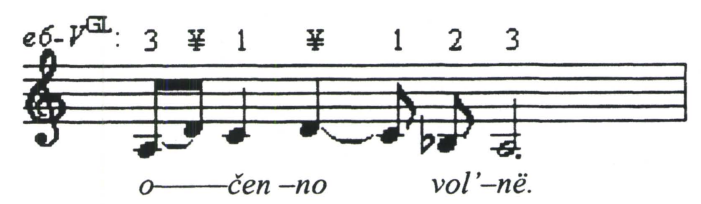

However, in the first stanza the women also modulated to the root $g 6-I^{\mathrm{GL}}$ which did not happen in later stanzas. The melodic progressions of this song are interesting especially in the second stanza but there is no room for details.
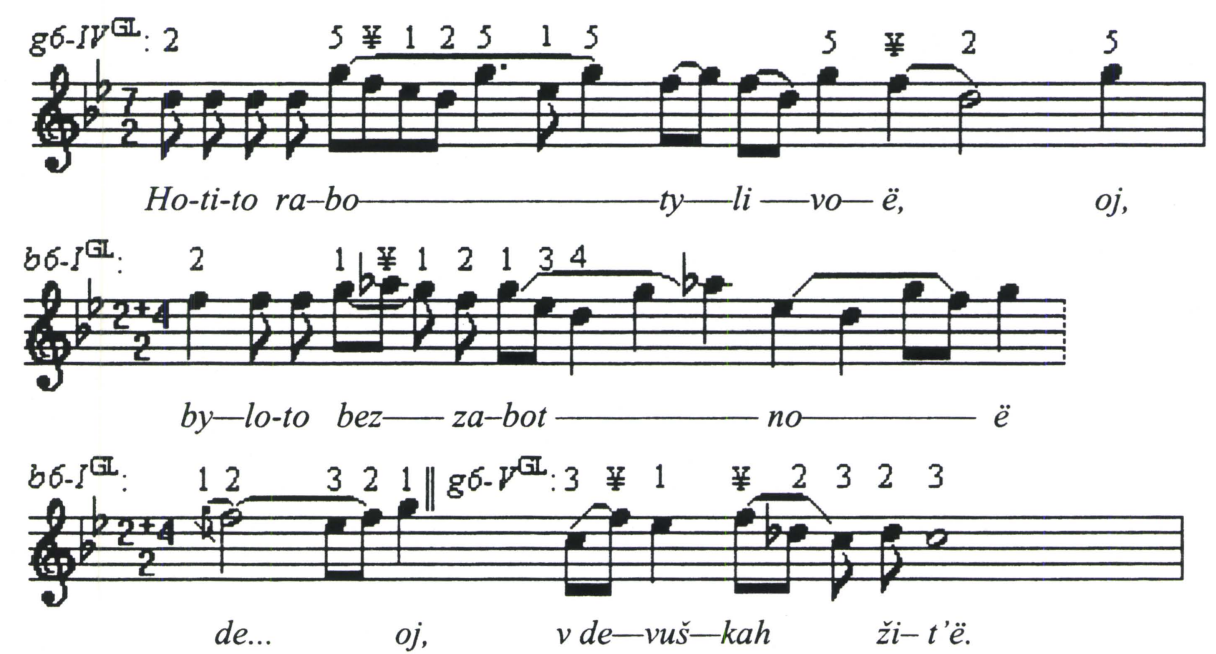

Figure 11. A slightly simplified reproduction of the first stanza of a drawn-out melody tape recorded in Šil'tija in 1977 (after Krasnopol'skaja 1987, I-14, pages 50-52). The prime mode of the whole performance is $g 6-I V^{\mathrm{GL}}$. In the first stanza the singers also visit the root $b$ flat 6-I ${ }^{\mathrm{GL}}$ (lines two and three). The closing formula at the end of the stanza is based on the root $g 6-V^{\mathrm{GL}}$. (The original transcription is in $a$ minor and an octave lower.)

One of the most complex among these songs is a drawn-out melody Cto že, cto ty in Figure 12. All the stanzas are melodically and metrically different from each other but it seems as if the song is based on a chain of modulating roots with the structure of $I V^{\mathrm{GL}}-V I^{\mathrm{GL}}-I V^{\mathrm{GL}}-I V^{\mathrm{GL}}-V^{\mathrm{GL}}-V I^{\mathrm{GL}}$. The prime character of the melody is the interplay of the roots $V I^{\mathrm{GL}}-I V^{\mathrm{GL}}-V^{\mathrm{GL}}-V I^{\mathrm{GL}}$. Cognates of the song can be found in many regions of European Russia. Its complexity is exceptionally high but its architecture suggests, firstly, an ancient origin, and secondly, a perfect competence in composing melodies based on the Proto-Indo-European pentatonic root system.

The $3^{\text {rd }}$ stanza in Figure 12 starts on the pentatonic basic tone $5\left(c \#^{1}\right)$ and the pentatonic marker 5-4-3 is intoned twice. The modulation to $b-V I^{\mathrm{GL}}$ occurs in tones $d^{1}$ and $b$ which are the $4^{\text {th }}$ and $5^{\text {th }}$ degree of this root. On the second line the singers modulate to $f \# 6-I V^{\mathrm{GL}}$ and the line is closed by the pentatonic marker 3-4-5 progressing in a reverse direction, that is, terminating on the upper octave $\left(5^{2}=f \#^{1}\right)$ of the 
basic tone 5. On the third line the root $I V$ is transposed from $f \#$ a fifth higher to $c \#^{1}$, and the line ends on the $3 \mathrm{rd}$ degree $\left(\mathrm{f \#}^{\mathrm{l}}\right)$ of this mode. On the fourth line the melody is modulated a fourth downwards to $g \# 6-V^{\mathrm{GL}}$ and the line is ended by tone $b$ which is the 4th pentatonic degree of this mode but also the basic tone of the following root $b 6$ $V I^{\mathrm{GL}}$. The last line of Figure 12 is beautifully ended by a cadence composed of the pentatonic marker 5-4-3-5. In all the stanzas the final cadence is a variant of this very same progression in $b 6-V I^{\mathrm{GL}}$ having the pentatonic basic tone 5 as the finale of the stanza. This complex song has its specifically ancient musical logic the memory of which is remote to all but a few in Europe.
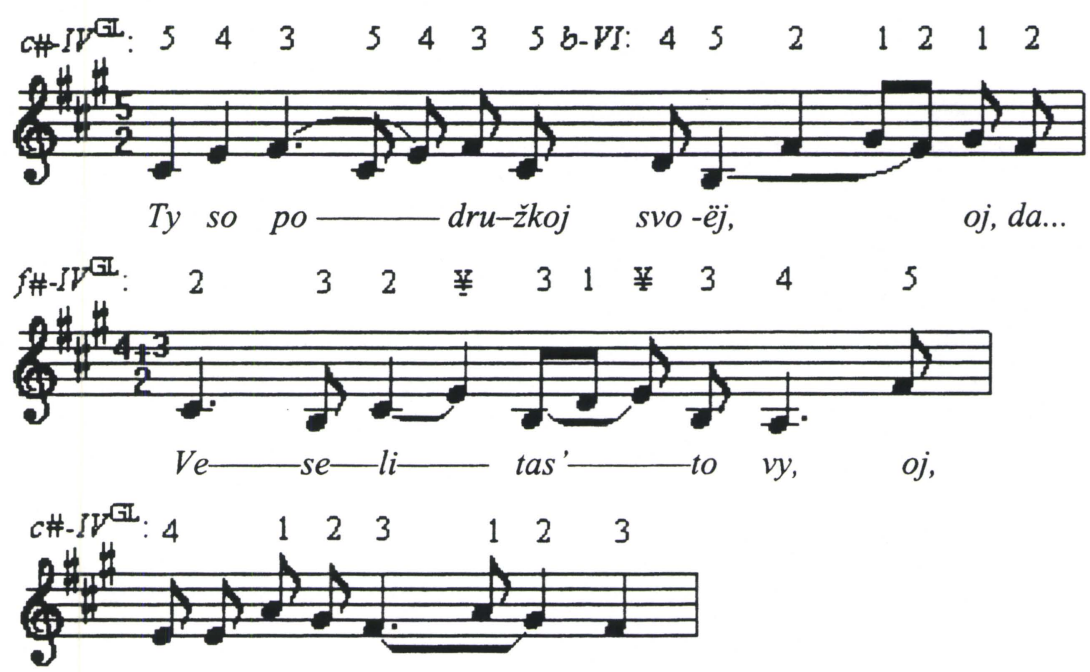

vy mo-i po-dru—žki,
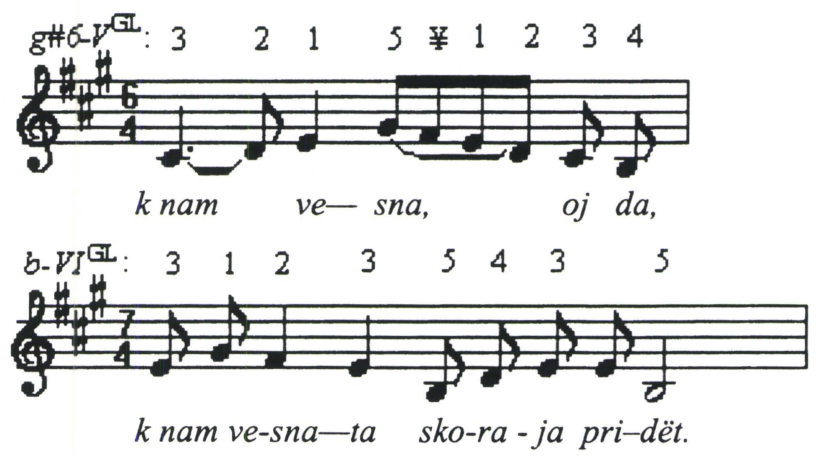

Figure 12. The higher part of the third stanza of a two-part drawn-out song published by Krasnopol'skaja (1987, I-4, pages 26-29). The song is a long chain of modulations. See the text. 


\section{A Comment and a Question}

Item I:3 was phonographed in 1926 by Evgenij Gippius and Zinaida Eval'd in the village of Botvišcina (Figure 13). There are no accidentals in the published version of this drawn-out song. As it stands now, it represents a tune in the mode $d^{1} 6$ - $V I^{\mathrm{GL}}$. However, the original phonogram in the Puškin House, St. Petersburg (Sound Archive, tape \# 33DM 1528, no. 32-0049:1), reveals that there must have been a printing error in the transcription. On the surface level, the melody was primarily sung in the descending tetrachord $c^{2}-b^{1}$ flat $-a^{1}$ flat $-\underline{G}^{1}$. This might be either a derivative of the root

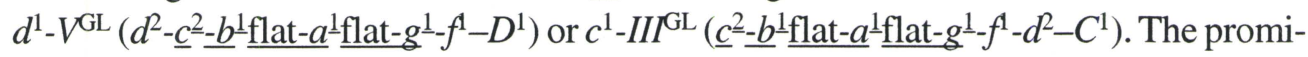
nence of note $c^{2}$, melodic progressions untypical of the root $V^{\mathrm{GL}}$, and the modulation to the "Oriental" mode with the wide second $b^{1}-a^{1}$ flat at the end of the tune, suggest that the root is $c^{1}-I I I^{\mathrm{GL}}$ with the pentatonic degree $2\left(g^{1}\right)$ as the final tone. In that case, $b^{1}$ flat is the auxiliary tone $¥$. This might explain why this very same tone is vague in pitch. At the end of the song the singer transformed $b^{1}$ flat to $b^{1}$ which modulates the mode $c^{1} 6-I I I^{\mathrm{GL}}$ to a new modality related to, for instance, Turkish Hicaz and the AhavahRabba of the medieval Jews.

The Hicaz-like mode $g^{1}-a^{1}$ flat $-b^{1}-c^{2}$ is far from unexceptional in European folk song ${ }^{3}$. Therefore it is quite possible that the singer of Figure 13 modulated deliberately. Actually, she started her song in this very mode but changed $b^{1}$ soon to $b^{1}$ flat. That she returned to $b^{1}$ natural in the fourth stanza, may suggest, however, that here we do not have a case of modulation but a recording of a style of singing in which the pitches are not always intoned quite precisely. On the other hand, the PIE root III GL, which transformed to harmonic minor during the Medieval Western Europe, is related to modes of the Hicaz type because the two activate the same kind of mood in the listener.

\footnotetext{
3 There are melodies in Finland and Scandinavia having the pentatonic 2nd degree as the finale. In these the melody progresses in ways similar to this one.
} 
$3^{\text {rd }}$ :
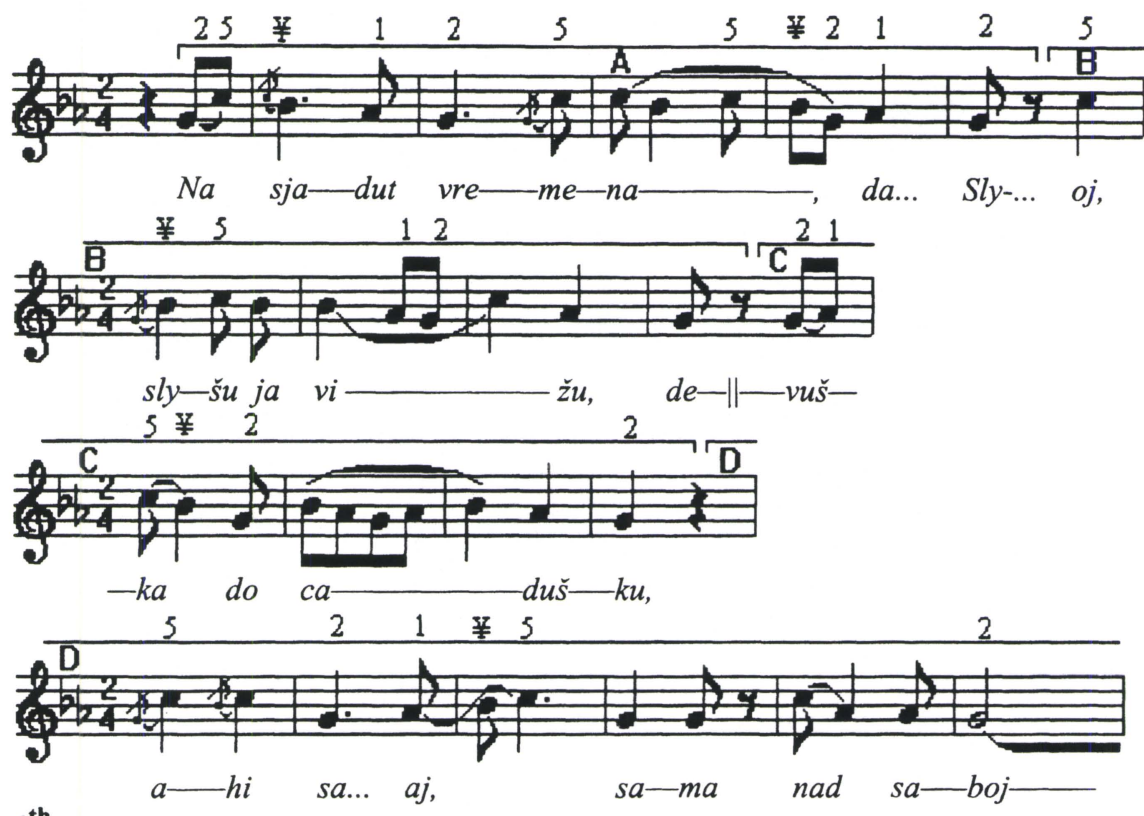

$4^{\text {th }}$
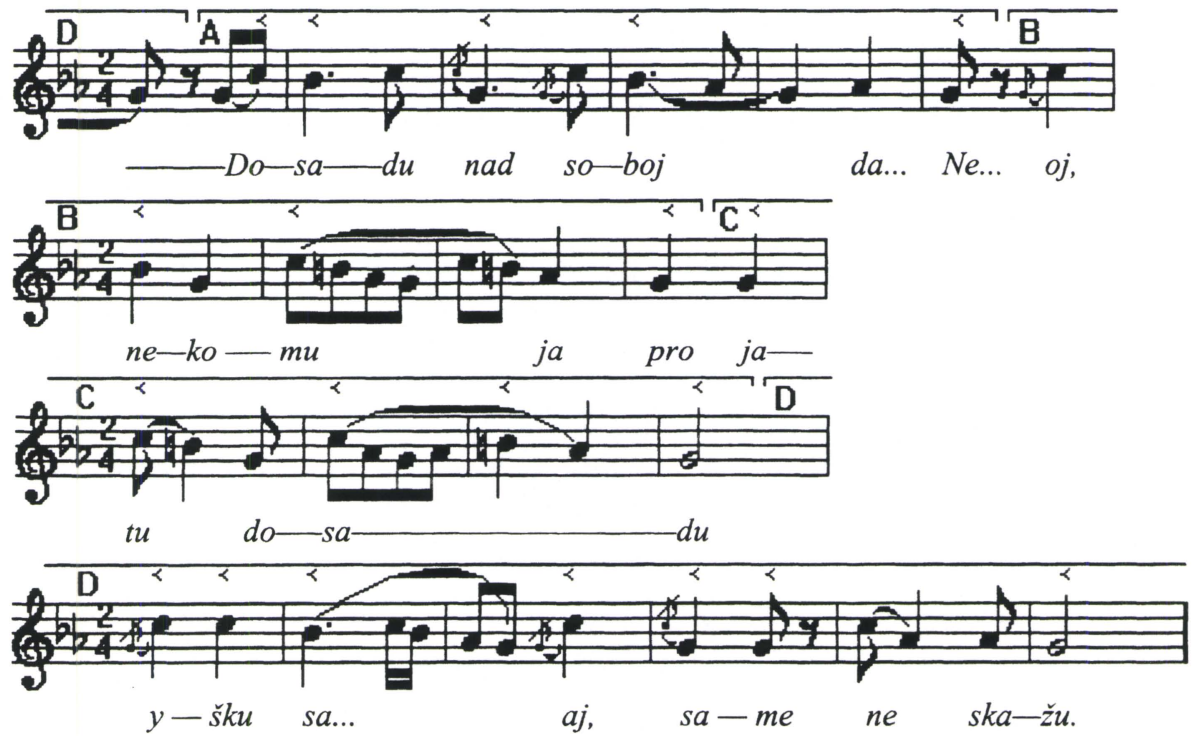

Figure 13. The drawn-out song I-3 (Krasnopol'skaja 1987, pages 24-25) reinterpreted by the present author according to the original recording in 1926. The source: The Pushkin House Sound Archive, tape 33DM 1528, No. 32-0049:1. Here are stanzas 3 and 4. The scale $g^{1}-a^{1}$ flat $-b^{1}$ flat $-c^{2}$ is a part of the root $c^{1}-I I I^{\mathrm{GL}}$. As seen on lines $\mathrm{B}$ and $\mathrm{C}$ of the fourth stanza, the singer changes $b^{1}$ flat to $b^{1}$ natural. Did she modulate or did she sing imprecisely? The melody seems to be constructed of four melodic sections A-B-C-D. The singer punctuates tones in a way marked below them in the 4 th stanza. This revised transcription differs in many ways from the Gippius-Krasnopol'skaja transcription which best suits to those familiar with Russian. 


\section{The Transonegan Collection of Laments}

In the Appendix of the Krasnopol'skaja collection there are 18 laments a short analysis of which is in Table 3. Because the published transcriptions are given in various "keys", the information of Table 3 is synchronised in Figure 14 which shows that the laments are based on the PIE roots $I^{\mathrm{GL}}\left(\sum=2\right), I I I^{\mathrm{GL}}\left(\sum=7\right), I V^{\mathrm{GL}}\left(\sum=7\right)$ and $V I^{\mathrm{GL}}\left(\sum=2\right)$.

\begin{tabular}{|c|c|c|c|c|}
\hline & THE BRIDE IS & & & STYLISTIC \\
\hline Item & LAMENTING TO: & Modal structure & $<$ Modal root & BACKGROUND \\
\hline VII-1 & her aunt and parents & $f^{1}-g^{1}-a^{1}$ flat $-b^{1}$ flat $-c^{2}$ & $<\operatorname{Root} c 6-I V^{\mathrm{GL}}$ & Old Karelian \\
\hline VII-2 & her friend in bajna & $f^{1}-g^{1}-a^{1}$ flat $-b^{1}$ flat $-c^{2}$ & $<\operatorname{Root} c 6-I V^{\mathrm{GL}}$ & Old Karelian \\
\hline VII-4 & her brother & $f^{1}-g^{1}-a^{1}$ flat $-b^{1}$ flat $-c^{2}$ & $<\operatorname{Root} c 6-I V^{\mathrm{GL}}$ & Old Karelian \\
\hline VII-5 & her mother & $g^{1}-a^{1}-b^{1}-c^{2}-d^{2}-e^{2}$ & $<g^{1}-D o+g 7-I^{\mathrm{GL}}$ & ?Slavo-Finnic \\
\hline VII-6 & her maiden friends & $a-b-c^{1}-d^{1}-e^{1}$ & $<a-L a+e 6-I I I^{\mathrm{GL}}$ & Finnish-Karelian \\
\hline VII-11 & her mother, aunt etc. & $c \#^{1}-d \#^{1}-e^{1}[3-2-1]$ & $<$ Root $g \#-I I I^{\mathrm{GL}}$ & Old Karelian \\
\hline VII-12 & the parents, brothers & $c \#^{1}-d \#^{1}-e^{1}[3-2-1]$ & $<$ Root $g \#-I I I^{\mathrm{GL}}$ & Old Karelian \\
\hline VII-15 & her mother & $b-c \#^{1}-d^{1}-e^{1}-f \#^{1}$ & $<\operatorname{Root} f \# 6-I I I^{\mathrm{GL}}$ & Dvina Karelian \\
\hline VII-7 & discuss with her sister & $b$ flat $-c^{1}-d^{1}$ & $<\operatorname{Root} f-I^{\mathrm{GL}}$ & Balto-Slavic \\
\hline VII-8 & her godmother & $e^{1}-f \#^{1}-g^{1}[3-2-1]$ & $<$ Root $b-I I I^{\mathrm{GL}}$ & Balto-Slavic \\
\hline VII-9 & farewell her parents & $e^{1}-f \#^{1}-g^{1}[3-2-1]$ & $<$ Root $b-I I I^{\mathrm{GL}}$ & Balto-Slavic \\
\hline VII-10 & the group of suitors & $e^{1}-f \#^{1}-g^{1}-a^{1}[3-2-1-¥]$ & $<$ Root $b 6-I I I^{\mathrm{GL}}$ & Balto-Slavic \\
\hline \multirow[t]{2}{*}{ VII-13 } & welcome the relatives and & & & \\
\hline & friends to her wedding & $c \#^{1}-d \#^{1}-e^{1}-f \#^{1}-g \#^{1}$ & $<$ Root $g \# 6-I V^{\mathrm{GL}}$ & Slavic \\
\hline VII-14 & prepare herself to bajna & $c \#^{1}-d \#^{1}-e^{1}-f \#^{1}-g \#^{1}$ & $<$ Root $g \# 6-I V^{\mathrm{GL}}$ & Slavic \\
\hline \multirow[t]{3}{*}{ VII-16 } & the lost of her free will & $b-c \#^{1}-d \#^{1}-e^{1}$ & $<\operatorname{Root} f \# 6-V I^{\mathrm{GL}}$ & Slavic \\
\hline & THE MAIDEN WHO PREPARES & & & \\
\hline & THE LAST BANJA LAMENTS TO: & & & \\
\hline VII-17 & describe her work & $b-c \#^{1}-d \#^{1}-e^{1}$ & $<\operatorname{Root} f \# 6-V I^{\mathrm{GL}}$ & Slavic \\
\hline \multirow[t]{3}{*}{ VII-18 } & describe her work & $f^{1}-g^{1}-a^{1}-b^{1}$ flat & $<$ Root $d-I V^{\mathrm{GL}}$ & Balto-Slavic \\
\hline & THE MOTHER IS LAMENT- & & & \\
\hline & ING TO THE BRIDE TO: & & & \\
\hline VII-3 & wake her up & $f^{1}-g^{1}-a^{1}$ flat $-b^{1}$ flat $-c^{2}$ & $<$ Root $c 6-I V^{\mathrm{GL}}$ & Old Karelian \\
\hline
\end{tabular}

Table 3. The Transonegan wedding laments in Krasnopol'skaja 1984, pages 142-165 with some rudimentary data of context, some results from the modal analysis and an approximation concerning the relation of style to some ethnic styles. The dialectal word bajna refers to 'sauna' or bathroom generally met with in the Russian form banja. 


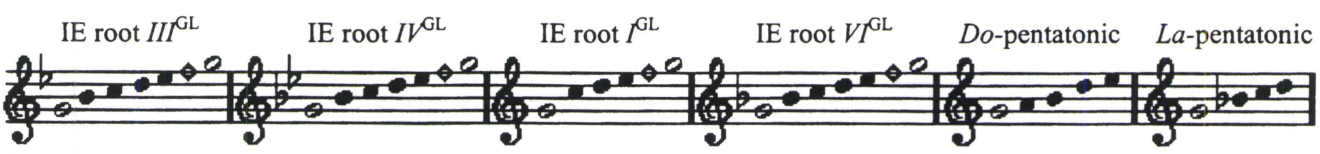

Figure 14. The laments in Table 3 are based on these six modal roots all having $g^{1}$ as the basic tone. The open note refers to the pentatonic basic tone (also having 5 as its symbol). The diamond refers to the auxiliary tone $¥$ which enlarges the pentatonic root (like $g-I I I^{\mathrm{GL}}$ ) a late pentatonic hexachord (like $g 6-I I I^{\mathrm{GL}}$ ).

The first two laments are based on verses seen in Figure 15.B. The melodic progression is closely related to the ancient Baltic-Finnic and especially Karelian runo style. A specific trait peculiar to many of the Finno-Ugric melodies in general is the fact that the final tone also is the lowest. The third lament belongs to the same group of melody but is more ambiguous because of the progression frequently met with in Scandinavian and Finnish pastoral tunes in the root $I I I^{\mathrm{GL}}$. Because the pentatonic 4th degree is missing, the identification remains as the $I V^{\mathrm{GL}}$ only because of the melodic curve common to the three tunes preceding.

A:

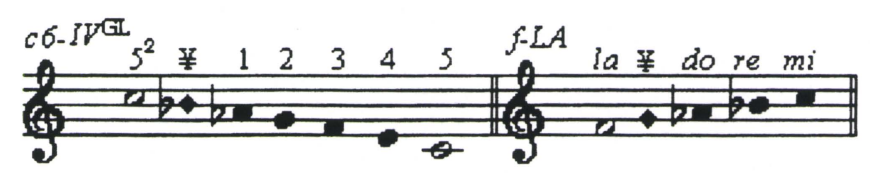

B:
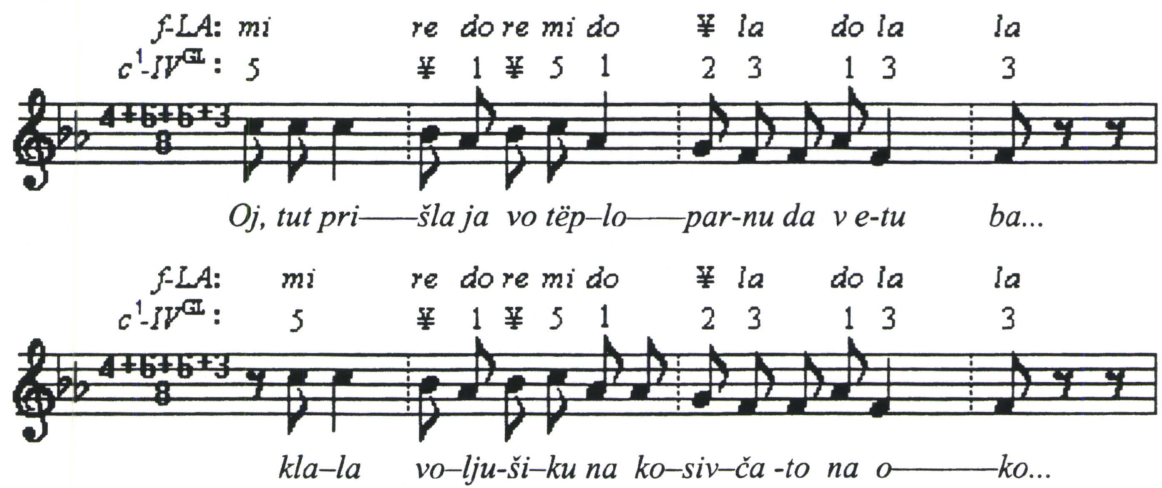

C:

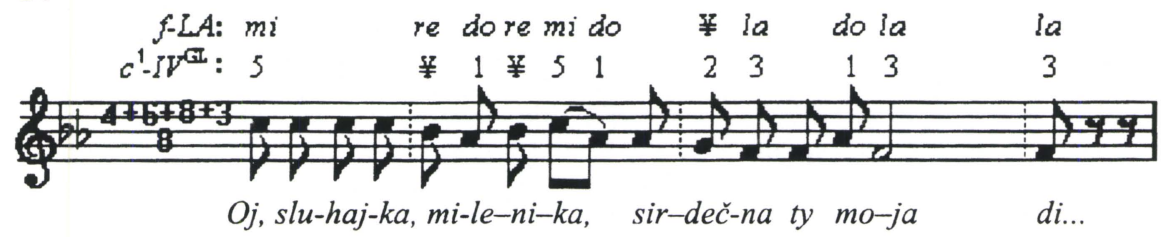

Figure 15. Verses representing the basic structure of the laments VII-1, VII-2 and VII-3 in the Krasnopol'skaja collection. The tones are symbolised here both by the PIE numbers $1-5$ and the anhemitonic symbols $l a-d o-r e-m i$. The sign $¥$ refers to the auxiliary tone in both patterns. -15 .A. The Proto-Slavic mode $c 6^{1}-I V^{G L}$ and the Old-Karelian $L a$-pentatonic modal root. - 15.B. Two verses from Krasnopol'skaya 1984, VII-2, page 146. - 15.C. A verse from Krasnopol'skaya 1984, VII-3, page 147. 
A striking fact in these three melodies is the strong $L a$-pentatonic descending deep structure of mi-re-do-la $=c^{2}-b^{1}$ flat- $a^{1}$ flat- $f^{1}$ with $f^{1}$ as $L a$. This deep structure explains the untypical cadence closing the double line as well as the seeming ambiguity of the melody. The Slavic 4th degree $e^{1}$ flat does not fit the Finno-Ugric La-pentatonic system because it is beneath the basic tone. In conclusion these three laments can be said to be true North-Russian art because they are a fusion of the East Slavic hemitonic tradition and the Balto-Finnic anhemitonic tradition. It does not really matter whether we identify the modal root as $I I I^{\mathrm{GL}}$ or $I V^{\mathrm{GL}}$ since the deep structure is anhemitonic and only seemingly East-Slavic by origin.

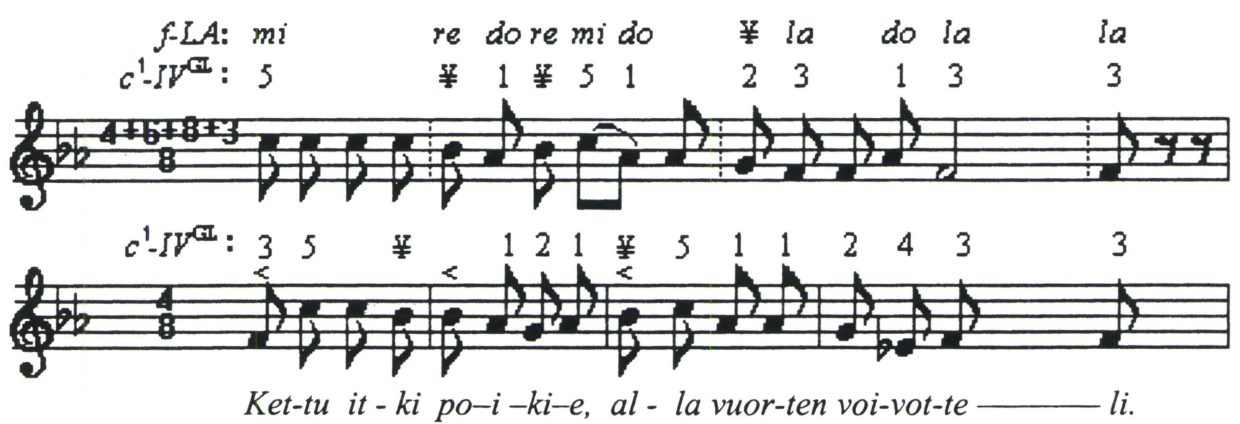

Figure 16. The comparison of Figure 15.C and an Old-Karelian melody in the same mode of $c 6-I V^{\mathrm{GL}}$ in Kalevala metre according to Leisiö 1996, nuotti 9, page 179, originally sung in Central Sweden.

We may compare Fig. 15.C with a song in Kalevala or runo metre recorded in 1926 among Central Sweden Finns according to the archaic Baltic-Finnic (or Old Karelian) style. This song clearly represents, however, an ancient Indo-European style obeying the root $c-I V^{\mathrm{GL}}$ with tone $e^{1}$ flat as its $4^{\text {th }}$ degree. This degree belonged to the old styles of the Proto Slavs and Proto Germans but not to the ancient style of the Baltic ProtoFinns. Both variants are syllabic which may represent a Finnic element in the Transonegan lamenting. Other Finnic elements may be the absence of the $4^{\text {th }}$ degree $e^{1}$ flat and the La-pentatonic flavour of the melody. Actually the emergence of this kind of a Russian mode $\left(f^{1}-g^{1}-a^{1}\right.$ flat $-b^{1}$ flat $\left.-c^{2}\right)$ seems to have occurred through a process shown below. The basic tone of the resulting new mode is the PIE 3rd degree $c^{2}$ corresponding to the Baltic Finnic $\mathrm{La}$. The main point to understand is that a pentachord is just a scalar abstraction. It is not a unitary mode. There may be many kinds of pentachords because the tones of one kind function differently from the tones of another. This means that we may encounter many kinds of homonymic "minor pentachords". In this case a Russian pentachord having a strong La-pentatonic anhemitonic elements in it may have emerged like this: 


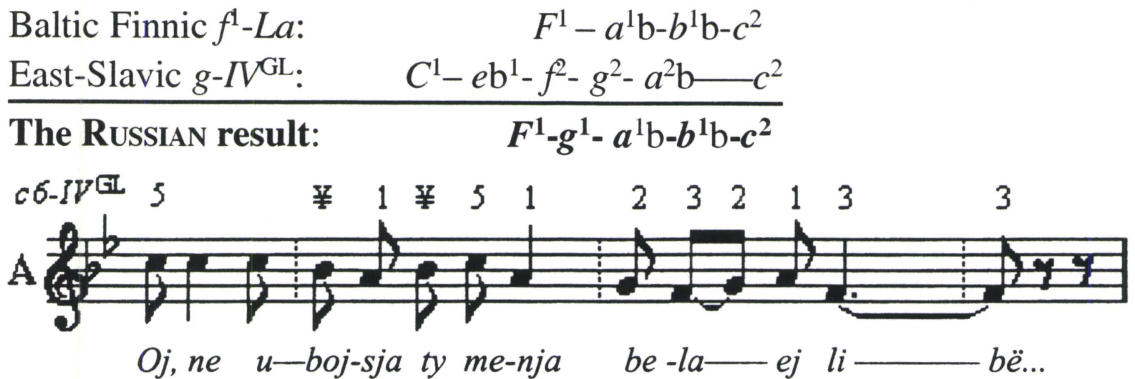

\section{g-I ${ }^{\text {GII }}: \begin{array}{lllllllllllllll}1 & 4 & 3 & 2 & 4 & 5 & 1 & 4 & 3 & 2 & 4 & \not & 5 & 4 & 5\end{array}$ \\ DO: la mi $¥$ sol $\mathrm{mi}$ do la $\mathrm{mi} ¥ \mathrm{sol} \mathrm{mi}$ re do $\mathrm{mi}$ do}

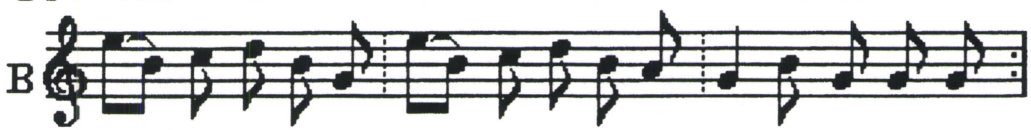

Na-ho-di-las'ja, kra-sna de-vuš-ka, na-gu-lja-la-sja.
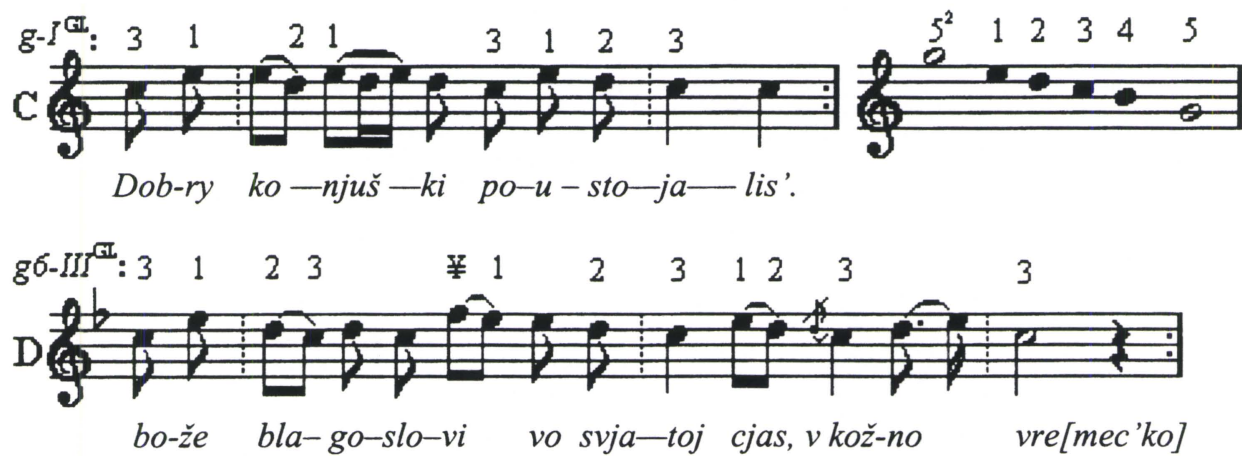

Figure 17. Transonegan laments given here with $g^{1}$ as the pentatonic basic tone.- $A$. The basic structure of item VII-4 in Krasnopol'skaja 1987, page 149. - B. The structure of VII-5 in Krasnopol'skaja 1987, page 150 , is a fusion of two pentatonic structures. The one is $g 7-I^{\mathrm{GL}}$ shown by the degree numbers above, and the other is $g$-Do shown by tone names $d o$, re... beneath the former. The symbol $\not \subset$ is for the "killer" of the pentatonic marker $g-b-c$. On the other hand the very same tone is the degree re of the $D o$ system. All in all, the tune is ambivalent and there may be a glimpse of Saame melody formation in the two first lines differing from each other by one tone $\left(a^{1}\right)$ only. $-C$. The structure of item VII-7 in Krasnopol'skaja 1987, page 151, is typical of the archaic Balto-Slavic singing according to the trichordic micro-mode based on the root $g-I^{\mathrm{GL}}$, which is here given as the tail of Fig 17.C. $-D$. The last verse-pair of item VII-10 in Krasnopol'skaja, page 155, is a good example of an archaic Balto-Slavic micro-mode in $g 6-I I I^{\mathrm{GL}}$, that is, a mode also having the auxiliary tone $¥=f^{2}$.

Lament No. VII-4 is based on a simple double verse seen in Figure 17.A. Even though the La-pentatonic cadence la-do-la is not present, the Old Karelian syllabic style of laments is as clear as the melodic progression typical of the IE root $g 6-I V^{\mathrm{GL}}$. Item VII5 is difficult to identify with any local style area. This lament was sung by the bride to her mother just before the weddings. The melody is a fusion of two pentatonic structures as seen in Figure 17.B. Items VII-7, VII-8 and VII-9 represent an archaic style of 
the Balto-Slavic micro-modes going back presumably to the late Neolithic time. They are, however, based on the Proto-Indo-European pentatonic roots. Item VII-7 is composed of the degrees 1-2-3 of the root $I^{\mathrm{GL}}$ (Figure 17.C) and items VII-8 and -9 are based on the same degrees of the root $I I I^{\mathrm{GL}}$. Item VII-10 belongs to the same group even though the singers also once used the auxiliary tone $¥$ (Figure 17.D).

In 1905 P. Jaryševa sang two laments (VII-11 and VII-12; see Figure 18.A) in the village of Velikaja Niva. Her songs are trichordic derivatives of the root $I I I^{\mathrm{GL}}$. However, they differ from the former Balto-Slavic laments by their melodic style which can frequently be found in Karelia. In the village of Šun'ga P. I. Mošina sang two laments (VII-13 and VII-14) in 1886. They move in the root $I V^{\mathrm{GL}}$ in a way which is typical of the northern East Slavic singing (Figure 18.B). It seems to the author that this style is clearly more recent than the style here called Balto-Slavic. One sign of relative recentness of style is the fact that the song is opened by the auxiliary tone $¥$ which also seems to have been quite a common trait in medieval popular tunes in West Europe.

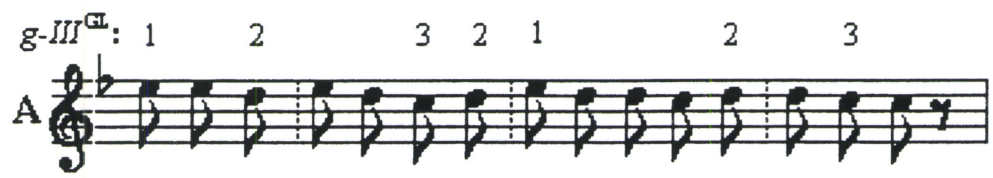

Oj, u mi-nja kak, u o-bi-di-noj kras-noj de-vu-ški,

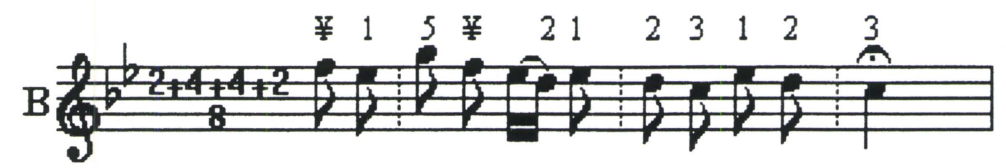

Na dve, na tri na u-roc'-nyh na ne-de[-ljuški]

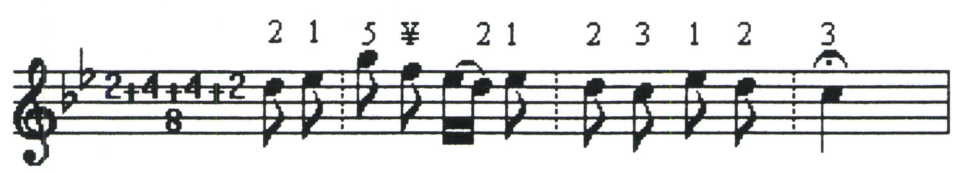

$u$-žo daj-ko mne ruc'-no-e ru-ko-del'[-icë].
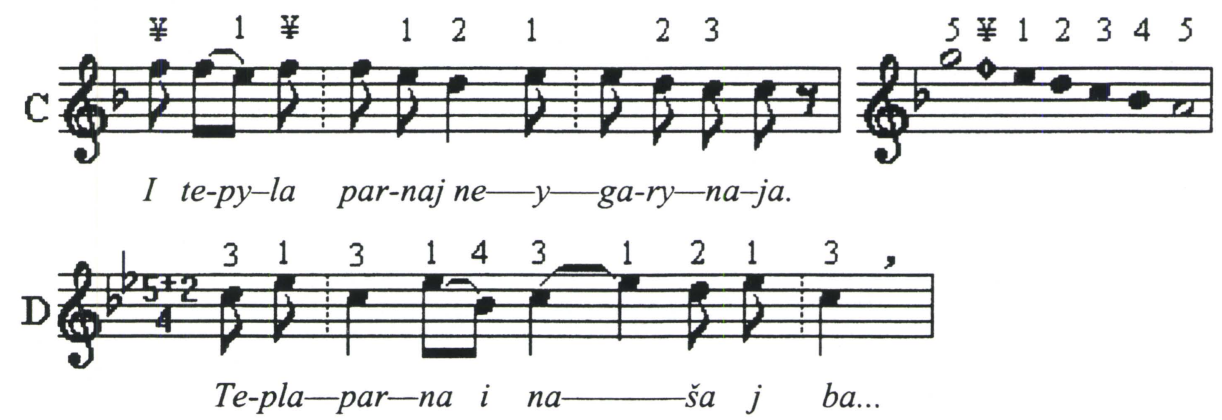
Slavic in character are the tetrachordic items VII-16 and VII-17, too, both having $V I^{\mathrm{GL}}$ as their modal root. Actually these two are the only ones of this kind among the present laments. The former one was tape recorded in 1977 in the village of Kosmozero. The latter lament from the village of Lambazrecej is an echo from 1884, and also was tape recorded a century later. The two variants share the same modal root and are closely related at all levels of music. The extract in Figure 18.C exemplifies both of them well. The toponym Lambazrecej is a combination of Veps lambaz 'sheep' and Russian rucej 'ditch; brook', and it is common as a place name among the Baltic Finns (like Lammasoja 'Sheepbrook' in Finland). - These two laments (items VII-16 and -17) are lacking the pentatonic degree 4 ( $b^{1}$ flat). It is not therefore possible to argue with any certainty that the singers had the root $V I^{\mathrm{GL}}$ in their minds. They could also have cenceived the root $I^{\mathrm{GL}}$ with tone $b^{1}$ as its 4th degree. (The last mentioned was transformed into the tonal major mode in medieval West European folk music.) Because the mood in these laments is far from that peculiar to the root $I^{\mathrm{GL}}$ (or to major), it is most probable that in these two cases we are dealing with the root $g$ - $V I^{\mathrm{GL}}$ which is always a bit confusing to a modern listener.

The most unexpected among the present laments is item VII-18 (Figure 18.D). Its melody differs in style from all other laments in the Krasnopol'skaja collection. Melodies like this can frequently be found in East-Lithuanian archaic songs especially in Aukštaitija. Some Aukštaitijan traditions seem to go back to the ancient Balto-Slavic culture which was not yet clearly segregated into Proto-Baltic and Proto-Slavic branches ${ }^{4}$. This melody may represent archaic style known by singers preceding the Proto-Slavic culture, no matter how long back in time we dare to locate it. As one of the archaic features is the descending melody line and the fact that the mode is based on the pentatonic degrees $1,2,3$ and $4\left(b^{1}\right.$ flat- $\left.a^{1}-g^{1}-f^{1}\right)$ of the root $d^{1}-I V^{\mathrm{GL}}$ with the 3 rd degree $\left(g^{1}\right)$ as the finale.

To conclude, we may suggest that the wedding laments of the North-Onegan peninsula are a fusion of several stylistic layers coming from different populations. At

${ }^{4}$ On the hypothesis of the Balto-Slavic background of some Indo-European modalities, see Leisiö in print.

Figure 18 (see previous page 208). Transonegan laments transposed here with $g^{1}$ as the pentatonic basic tone. $-A$ : Verse no. 4 of item VII-12 in Krasnopol'skaja 1987, page 157, represents a typical Old-Karelian trichordic lament style based on $g-I I I^{\mathrm{GL}}$. $-B$. Lines 2 and 3 of the lament VII-13 were originally sung in Šun'ga in 1886 (Krasnopol'skaja 1987, VII-12, 158-159). The style is East Slavic and the modal root is $g 6-I V^{\mathrm{GL}}$. The fact that the final tone is the lowest one may or may not be of Baltic Finnic influence. The pentatonic basic tone is the highest one $(=5)$. $-C$. A typical verse of the lament VII-17 in Krasnopol'skaja 1987, pages 163-165. The root is $g 6-V I^{\mathrm{GL}}$ and the melody progresses in a way typical of the archaic East Slavic style. The late pentatonic $g 6-V I^{\mathrm{GL}}$ is exemplified as the tail of example C. $-D$. The second verse of the lament VII-18 Krasnopol'skaja 1987, page 165. The tune is an astonishingly archaic Balto-Slavic representation of the root $g-I V^{\mathrm{GL}}$. 
the present stage of knowledge we may first say that these melodies are mainly based on modal roots $I V^{\mathrm{GL}}$ and $I I I^{\mathrm{GL}}$ of Indo-European origin. The Baltic Finns got acquainted with these roots thousands of years before the East Slavs appeared in the Northwest Russian forests. The Slavs had their rules to form melodies, the Baltic Finns had theirs, but the two populations used the same roots as their tone supply. The Baltic Finns also had song traditions according to their much older anhemitonic pentatonic modalities especially those of $\mathrm{Do}$, Sol and $\mathrm{La}$. They seem to have been popular ever since the Mesolithic epoch. Since the Neolithic era the Finno-Ugrians had become aware of the Proto-Indo-European modalities. - After the contacts with the East Slavs strengthened since the 10th century AD, the eastern Baltic Finns adopted more and more Slavic elements into their songs. Because of this their anhemitonic traditions retreated during the centuries. On the other hand, Finnic elements can still be found in the archaic fusion culture of the East Slavs, the early Russians and the eastern Baltic Finns. In the case of these Transonegan laments, the Karelian and Veps styles can clearly be identified and defined as different from Slavic style. We may bear in mind that syllabic singing was more typical of Karelian runo and even of lament styles while the anhemitonic elements may more probably come from the Old Veps than the Karelian singing.

\section{Fusion Melodies}

All "official" cultures of any modern and politically independent state in Europe are examples of a fusion culture which is a term for any cultural conglomerate of elements coming from diverse local sources. A good example is Romanian culture. The early dwellers in present Romania were the post-glacial indigenous Europeans who slowly melted in the Indo-European invaders. This conglomerate was known as the Dacian (that is, northern Thracian) culture which had become Romanised since the early 2 nd century $\mathrm{AD}$, and this new conglomerate adopted a great many cultural elements from many later populations, such as the Slavs, Goths, Hungarians, Turks etc. This also was the case in the formation of Russian culture.

There never was any Proto-Russian culture even though Proto-Slavic culture existed. By the term Old-Russian many researchers refer to some easternmost Slavic high cultures having late Proto-Slavic as their language. So, instead of an impossible cultural unity of "Proto-Russian", there were a great many local cultures composed of elements of the East-Slavic invaders and the local peoples, such as some Iranian populations to the north of the Black Sea, the Bolghars in the middle Volga and diverse Finno-Ugrians all over North-Europe -quite many of them starting to use Slavic as their language. From the historical point of view, the term "Russian" (as a nomina- 
tor of culture) refers to a fusion of diverse elements from diverse sources. From the point of culture history, the term "Russian" cannot be used as a synonym for "Slavic". This relation of synonymity is as impossible as is Finnish to Karelian or Saxon in England to Saxon in Germany. - To say that Staraja Ladoga was an old Russian trade town is correct, but to say that it also was an ancient East-Slavic town is not correct.

\section{D.1. Fusion Melodies Dominated by an Anhemitonic Modality}

Anhemitonic elements in the present Transonegan collection are not too obvious and quite often they escape the ears of a listener enculturated into 20th century western tonality. The bride's ritual wedding song of praise, Čto ni stojki po stojkam stojat, is seen in Figure 19.A. It comes from the village of Kašma and represents a style far from anything identifiable as East-Slavic, not to mention Indo-European as a whole. The melody only seems to be a "minor pentachord" by mode. It is an obvious realisation of the $a$-La-pentatonic modality of $L a-d o-r e-m i=a^{1}-c^{2}-d^{2}-e^{2}$ with $b^{1}$ as the auxiliary tone representing the 2 nd degree of $e-I V^{\mathrm{GL}}$. The poem seems quite structured and may possibly have an octosyllabic background idiom (like $\underline{\mathrm{Ni}}$, ma-li-no-vy li pru$t i-k i$ with syllables $n i$ and $m a$-constituting the first mora). In any case, the style is clearly syllabic (i.e. one syllable to one tone) and each text verse is composed of a triple repetition of the rhythmical nucleus.$\supset$. .

The richness of Russian culture as a fusion is concretely sensed in the Krasnopol'skaja collection. For instance, the next song of praise, Vo gorode krovat' etc. (IV61, -63, and -64 on pages 119-121) are deeply East-Slavic in style going back, in the mind of the author, to the traditions of the Neolithic singers of the Balto-Slavic subculture among the Indo-Europeans. The evidence is quite thin. However, their style is very well known in archaic Lithuanian singing. It is more logical to presume that the Lithuanian and Transonegan styles are related by genetics - than by diffusion from Lithuania to Northwest Russia or vice versa. The affect of the two groups of melody in the mind of a listener is too similar to doubt that they would not be genetically related. On the other hand, the affect of items IV-61 etc. is compelety different from that created by item IV-57 (in Fig. 19.A) which is presumed here to be a reminiscence of culture once known by the indigenous populations in Northwestern Russia - whoever they were by modern ethnic criteria.

A fascinating example of a bride's farewell song is in Figure 19.B. The main modality is $b$ - $L a$ but the lower part starts in $f \# 6-V^{\mathrm{GL}}$, modulates then to f\#6-IVGL and finally to the same $b$ - $L a$ modality as is the basis of the upper part. On the other hand, the upper and the lower parts simultaneously make a short visit to f\#6-IVGL. This kind of song is difficult to find beyond the Russian tradition anywhere in Europe. 

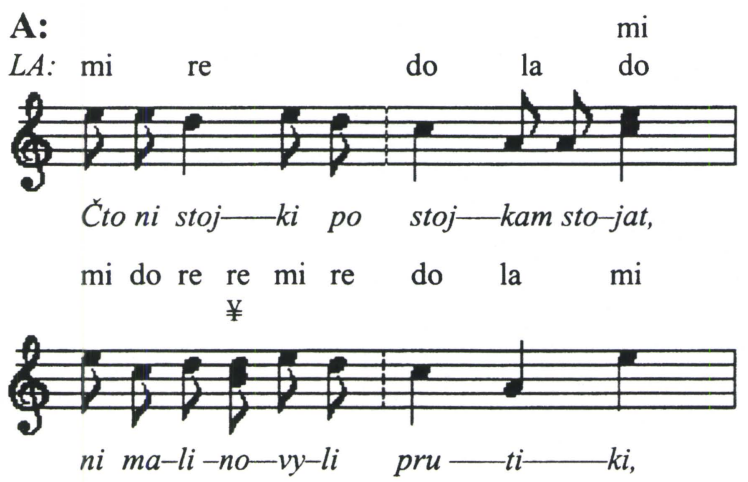

B:

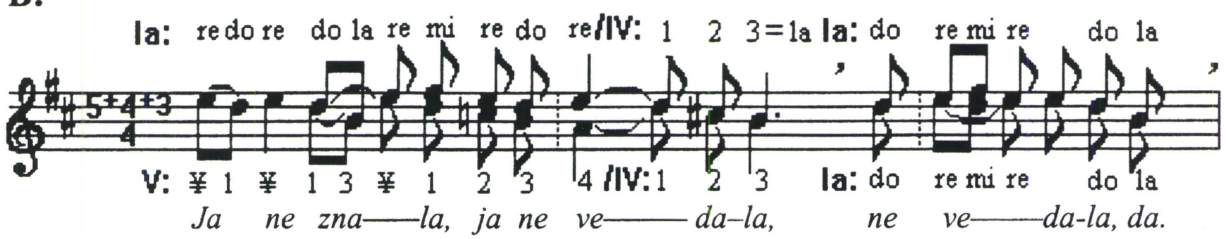

la: remire do re mi re do reflV: $123=1$ a la: do re do re do la

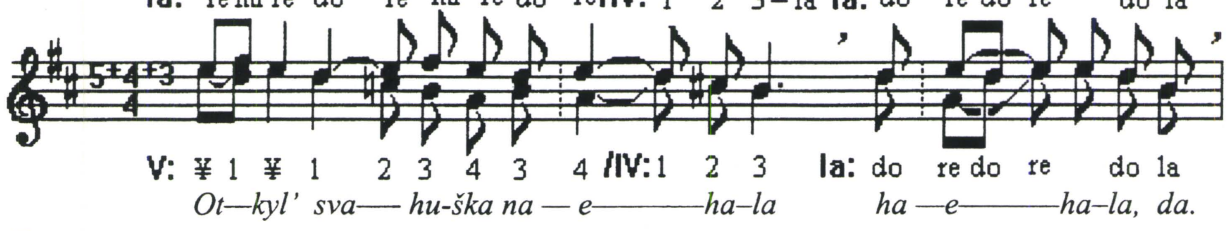

C:

d-SOL:

sol $¥ \mathrm{mi}$ la sol la sol re $¥ \quad$ mi re la sol
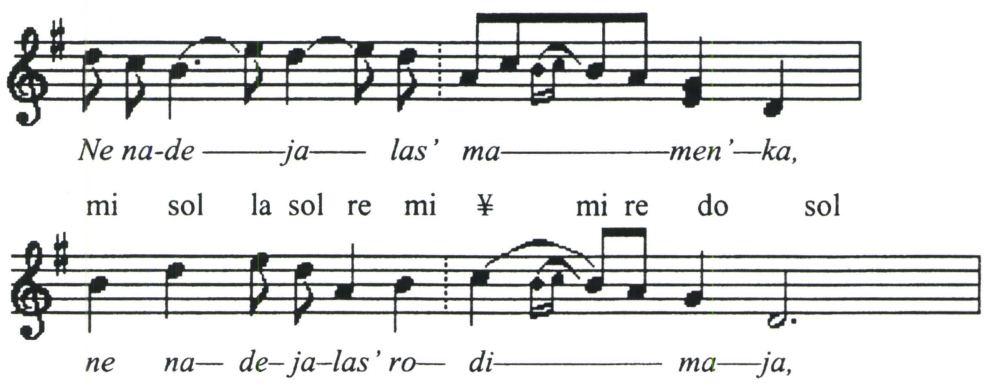

Figure 19.A. Verses 1 and 4 of an iterative song of praise after Krasnopol'skaja 1987, IV-57 (page 118) seem to represent a Finno-Ugric element in Russian culture. The source of the East Slavic impact in this anhemitonic melody is met with in the auxiliary tone $¥$ and the fact that the pentatonic basic tone $e^{2}$ (of the root $e 6-I^{\mathrm{GL}}$ ) functions as the finale of most verses - which trait is not shared by any FinnoUgric style which by contrary avoid tones beneath the final tone. $-B$. A bride's farewell song according to Krasnopol'skaja 1987, III-38 (pages 101-102). The upper part is modally an interplay of FinnoUgric $L a$ and Indo-European $V I^{\mathrm{GL}}$ while the lower part also uses the root $V^{\mathrm{GL}}$. In the knowledge of the present author a complex fusion style like this does not exist in any other Eurasian region but can only be found in Russian folk music in Russia. - C. A 19th century bridal farewell song from the village of Šun'ga. This is the first double verse after Krasnopol'skaja 1987, III-32 (page 94). The mode is $d$-Sol pentatonic with the additional tone $¥=c^{2}$ which is also the auxiliary tone $¥$ of the mode $d 6-I^{\mathrm{GL}}$. 
As already said along with Figure 10.B, the farewell songs III-32, -33 and -34 are melodically close to the East Slavic item III-31. However, they are different because of their inherently anhemitonic structure. This can be seen in Figure 19.C. The tune goes in the $d$-based $\mathrm{Sol}$ mode. Especially the cadencing formula mi-re-do-sol $\left(b^{1}-a^{1}\right.$ $\left.g^{1}-d^{1}\right)$ is quite typical of archaic Balto-Finnic and Saame songs. Another interesting feature in this tune is the text which may be interpreted as having the deep structure of eight morae. This can be demonstrated by the following table and can also be seen in Figure 19.C. However, the underlying IE mode $d^{1} 6-I^{\mathrm{GL}}\left(d^{1}-f^{1}\right.$ sharp- $\left.-g^{1}-a^{1}-b^{1}-c^{2}-d^{2}\right)$ can be identified as an East Slavic element which may explain the prominence of the degree $¥=c^{2}$ in the lower line of Fig. 19.C (syllable - $d i$-). It also explains the presence of $f^{1}$ sharp which appears once when the singers divide into two and form the trichord $f^{1}$ sharp- $a^{1}$ instead of only anhemitonic $a^{1}$. (Tone $f^{1}$ sharp is the 4th degree of the IE mode $d-I^{\mathrm{GL}}$.)

\begin{tabular}{|c|c|c|c|c|c|c|c|c|}
\hline The chain of eight morae: & 1 & 2 & 3 & 4 & 5 & 6 & 7 & 8 \\
\hline & $\mathrm{Ne}$ & $n a-$ & $d e-$ & $j a-$ & las' & $m a-$ & men' & $-k a$ \\
\hline & & $n a-$ & $d e-j a-$ & - las' & ro & $d i-$ & $m a-$ & $-j a$ \\
\hline & & $n a-$ & $d e-j a$ & -las' & vo & $\mathrm{ra}$ & $e$ & $z i t^{\prime}$ \\
\hline & $V$ odni & cjas, & vo- & $d n u$ & $m i-$ & $n u-$ & toš- & $-k u$ \\
\hline & Žar - & ko & žar - & ko & vo & $v y-$ & $\mathrm{SO}_{-}$ & kom \\
\hline & Žar- & ko & žar - & ko & vo & $s k o-j a$ & $-r o-$ & vy \\
\hline
\end{tabular}

The youth song in Figure 20.A was transcribed in 1916 after the village tradition of Sennaja Guba. The melody was also known in the former governments of Tver, Vjatka, Perm and Samara by the Volga river system. The mode might be interpreted as a pentachordic materialisation of the root $c 6-I^{\mathrm{GL}}$ with the $3 \mathrm{rd}$ degree $\left(f^{1}\right)$ as the finale: $C^{1}-\left[e^{1}\right]-f^{1}-g^{1}-a^{1}-b^{1}$ flat- $c^{2}$. However, this mode is also quite common in Lapland, Karelia, Estonia and Latvia but also found in North Russian Komi. It is quite propable that this kind of a melody with a prominent "lower fourth" as the finale represents an archaic non-Indo-European Sol pentatonic mode type (in $f$ ). In this case $b^{1}$ flat is the additional $¥$.

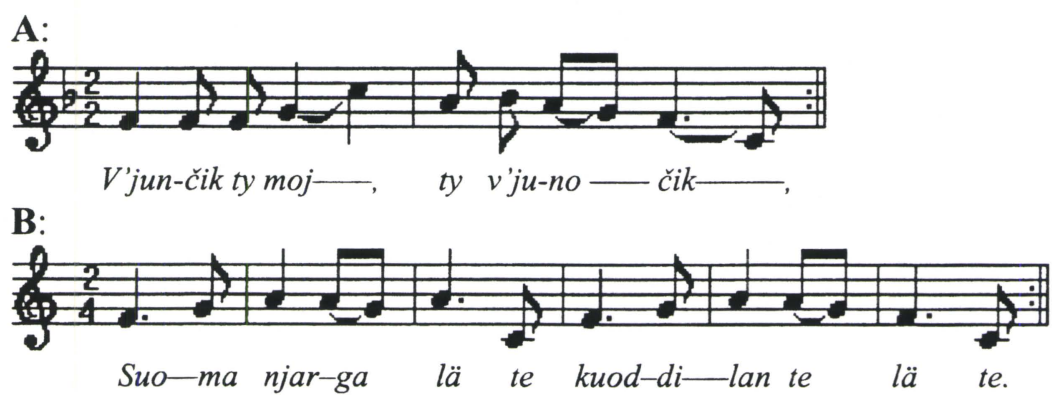




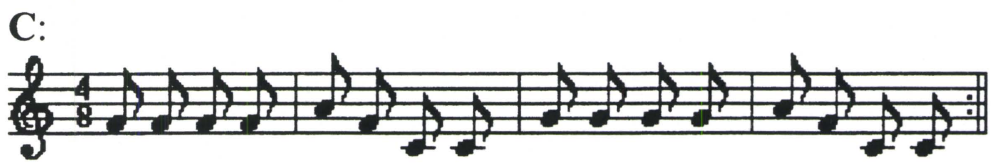

Mis sa si-ti-kas si-ri-sed, po-ri-kär-bes, mis po-ri-sed?

Figure 20.A. The first verse of a youth song from Sennaja Guba village after Krasnopol'skaja 1987, V-66 (page 124; transcribed in 1916). The melody is governed by the $f$-based $S o l$ mode. $-B$. A West Saame yoik from Utsjoki, Finland, after Launis 1908, nr. 640. - C. A lyrical song from NorthEstonian Koeru in 1909 after Tampere 1965, nr. 28.

The melody Ty, hozjain, veli da in Figure 21) is interesting when trying to understand the specific character of Russian folk song. Apparently this youth song melody represents a tune in $B \mathrm{~b}$ major with the chord progression IV-V-I, as can be seen at the beginning of the tune:

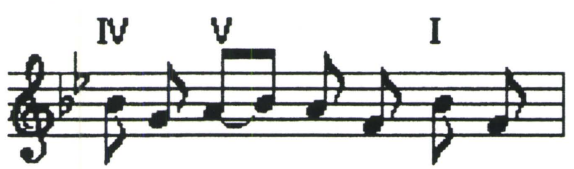

Ty, ho-zja-in, ve-li, da,

Imagine a group of lads singing alternatively with a group of maidens who were spinning and doing other regular autumn works. Songs so sung were kinds of courting songs with texts loaded with erotic symbolism. Boys and girls were singing accompanied with a simple accordion capable of producing these three tonal chords. In spite of the presence of the three tonal chords, the melody is not truly tonal. One reason is the unconventional chordal progression and the prominence of $f^{1}$ as the finale of each line. The tune in Fig. 21 sounds undeniably Russian - but on what grounds?

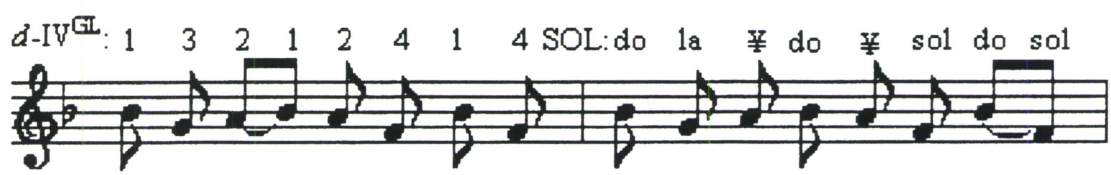

Ty, ho-zja-in, ve-li, da, gos-po-din, bla-go-slo-vi-

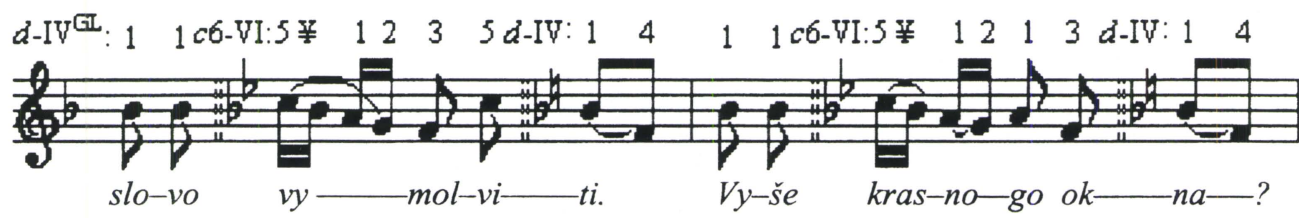

Figure 21. Two lines from a youth song sung in the village of Sennaja Guba and transcribed in 1916 (after Krasnopol'skaja 1987, V-71, page 129). The upper line materialises both the root $d-I V^{\mathrm{GL}}$ and the Sol pentatonic mode in $f$. The degrees of both varieties occur one after the other. The Sol pentatonic foundation is also active on the lower line but here only the modulations in the roots $I V^{\mathrm{GL}}$ and $V I^{\mathrm{GL}}$ are demonstrated. 
Krasnopol'skaja transcribed the first strophe of four verses $\left(\mathrm{AA}^{1} \mathrm{BB}^{1}\right)$ and the second strophe of three verses $\left(A A^{1} C\right.$ in which $\left.C=b^{1}+a^{1}\right)$ for her collection. The four verses seen in Figure 21 are $A A^{1}$ and $B^{1} C$. The structure of this song seems quite simple and logical. The double verse $\mathrm{AA}^{1}$ materialises the most typical root $I V^{\mathrm{GL}}$ in $d$. The melodic progression is typical and fully pentatonic. However, the melody is also structured by Sol pentatonic grammar in $f$ which is illustrated on the latter part of the upper line in Figure 21. The Sol pentatonic logic also governs lines B and C in which the most prominent tones are sol, la, do and $r e\left(f^{1}-g^{1}-b\right.$ flat $\left.{ }^{1}-c^{2}\right)$. This element, as powerful as it is, is mixed with the Proto-Slavic modalities. Verse $\mathrm{A}^{1}$ (= the beginning of the lower line in Figure 21) starts in $d-I V^{\mathrm{GL}}$, but modulates to $c-V I^{\mathrm{GL}}$ which governs the melody during the syllables $v y$-mol-vi-ti. The descending motive $c^{2}-b^{1}$ flat $-f^{1}$ is typical of Russian cadences and corresponds to the degrees re-do-sol in $f$-Sol mode. The modulations bring the melody first back to $d-I V$ (syllables $-t i$. $V y-\check{s} e$ ), then to $c-V I^{\mathrm{GL}}$ and finally back to the cadencing mode $d-I V$.

This melody, even if seemingly tonal, is a cleverly constructed combination of two hemitonic (Indo-European) root modes and the anhemitonic Sol mode. As it appears now, this individual tune is not ancient - even if its function as a part of the reciprocal relationships of the young people, and the active use of modulation, are ancient elements going back to the Proto-Slavic singing. On the other hand, the anhemitonic structure of Finno-Ugric origin (materialised by the tones $f, g, b$ flat and $c$ ) makes the style genuinely Russian.

\section{D.2. Fusion Melodies dominated by the PIE Root $\mathrm{I}^{G L}$}

The game song of the youth in Figure 22. A could be put under various subgroups in this article because the song modulates, and transposes as well as has a clear fusion character. The first hemistich (So vjunom ja hožu) is a bflat-Sol pentatonic progression. The latter part of the verse uses the same degrees but the cadence and the continuation of the melody forces us to conclude that the dominating mode is the fully pentatonic $b-I^{\mathrm{GL}}$. The presence of the $S o l$ mode is, however, inescapable. In the second verse the singers transpose the pentatonic basic tone a fourth lower to $f 6-I^{\mathrm{GL}}$. The tune ends on $b$ flat which makes it easy forsingers to return to the original mode $b$ flat$I^{\mathrm{GL}}$ when starting the next stanza. There is one more trick in the second stanza. Tone $a^{1}$ is impossible in mode $b$ flat- $I^{\mathrm{GL}}$. The auxiliary tone $¥$ should be $a^{1}$ flat. Here the singers had temporarily modulated to full pentatonic $c-V I^{\mathrm{GL}}$ which was widely favoured by the people (see Fig. 22.B). However, after this modulated hemiverse položu ja $v^{\prime}$ jun the singers returned to the original procedure, that is, transposed back to $f 6-I^{\mathrm{GL}}$. This song was widely known in North-west Russia. It is fascinatingly constructed and one can sense a kind of a medieval echo in it. 

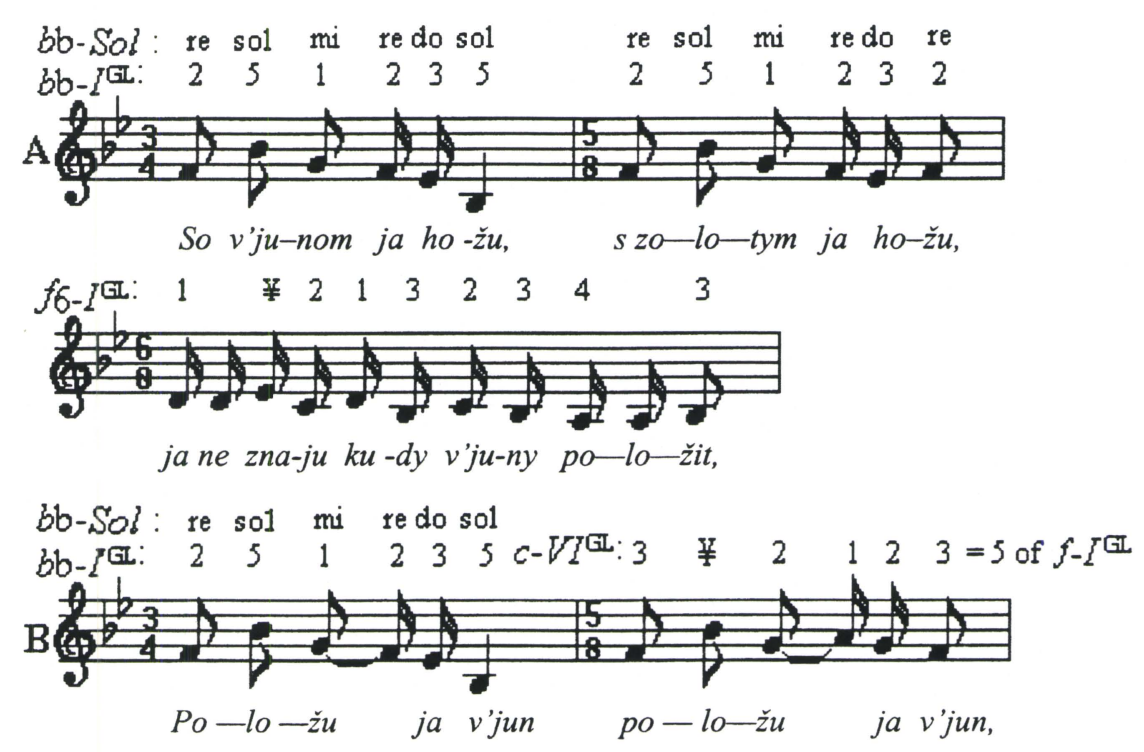

Figure 22.A. Verses $A$ and $B$ of the $A B B$-song V-65 in Krasnopol'skaja 1987, pages 123-124. The first verse is based on $b$-Sol influenced by the root $b$ flat- $I^{\mathrm{GL}}$. The second verse is in the same root but transposed a fourth lower to $f$. $-\mathrm{B}$. The first verse of the 2 nd stanza of the same song starts like the one in the 1st stanza but in the latter part of the verse a modulation to $c^{1} 6-V I^{\mathrm{GL}}$ takes place after which the melody goes on as in Fig. 22.A (ja ne znaju...).

\section{D.3. Fusion Melodies dominated by the PIE Root IV ${ }^{G L}$}

In Figure 23 there is a wedding song with a fascinating structure. There is a strong feeling of a $b$-La pentatonic flavour in the progression of the upper part when moving on the tones $b-d^{1}-e^{1}-f \#^{1}$. From another point of view the upper part is based on tones belonging to the full pentatonic structure of $b-I V^{\mathrm{GL}}$. The cadential descending movement of mi-re-la or 2-3-5 of $b-I V^{\mathrm{GL}}$ is one of the main symbols of Russian national song style. It is the hypothesis of the present author that the $L a$ pentatonic feature is not accidental but a materialisation of a stylistic pattern under the Russian folksong style. The lower part is also based on the root $I^{\mathrm{GL}}$ but now one fourth lower: f\#6$I V^{\mathrm{GL}}$. This is not a tune in $b$-minor but it is a late pentatonic melody having two tonal centers, (1) $b$ as the basic tone of $b$ - $L a$ and $b-I V^{G L}$ and (2) f\# as the basic tone of f\#6$I V^{\mathrm{GL}}$. This kind of structure is quite uncommon in other parts of Europe except Russia, and here we have elements which may give us clues to understand the reasons for the existence of a specific Russian style.

The drawn-out song in Figure 24 is interesting. It strictly materialises the root $c^{1} 6-$ $I V^{\mathrm{GL}}$. However, one section of the melody may be interpreted as a modulated part to the $L a$ pentatonic modality differing completely from the rest of the melody. We may compare the corresponding parts of the beginning of line two belonging to stanzas 2 
and 3. In one way we might identify them as the same. However, the singers may have had two different modal patterns in mind, due to which the two options conjure up different affect in the mind of a listener. As can be seen in Figure 24, this verse is as if sung according to the La pentatonic mode in the 2nd stanza while it is materialised according to the root $c^{1} 6-I V^{\mathrm{GL}}$ in the 3 rd stanza.

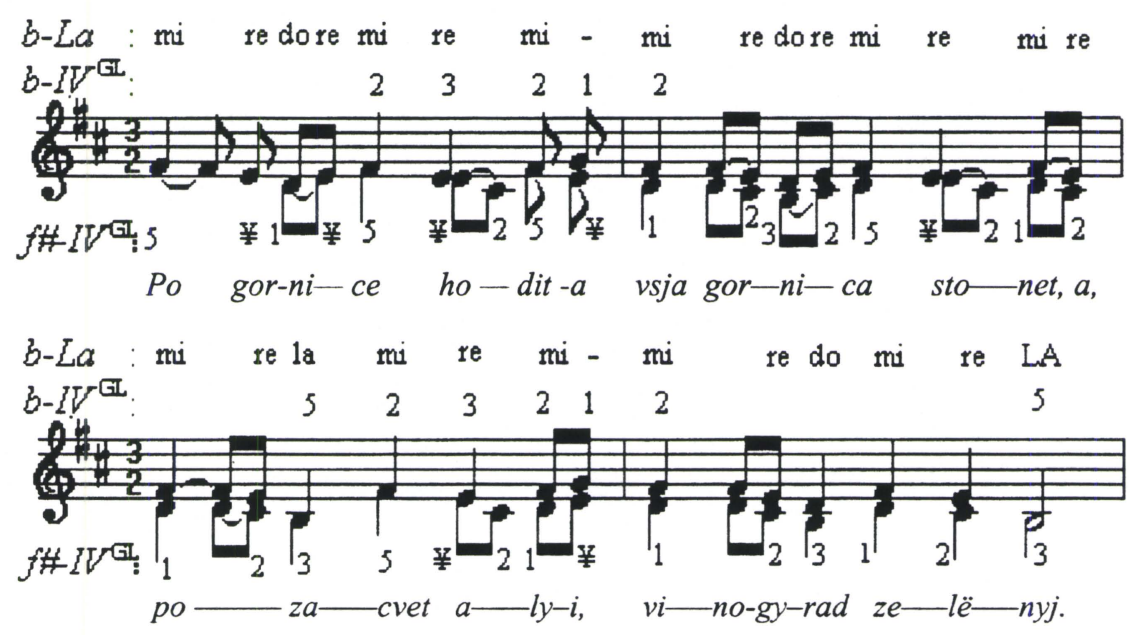

Figure 23. The third stanza of the wedding song IV-64 in Krasnopol'skaja 1987, pages 120-121. The dominating mode is $f \# 6-I V^{\mathrm{GL}}$ but it is also possible to sense $b$ - La pentatonic tetrachord $b-d^{1}-e^{1}-f \#^{1}$ and $b-I V^{\mathrm{GL}}$ in the upper part. The degree symbols above the staff refer to the upper voice; those under the staff refer to the lower part.

A:
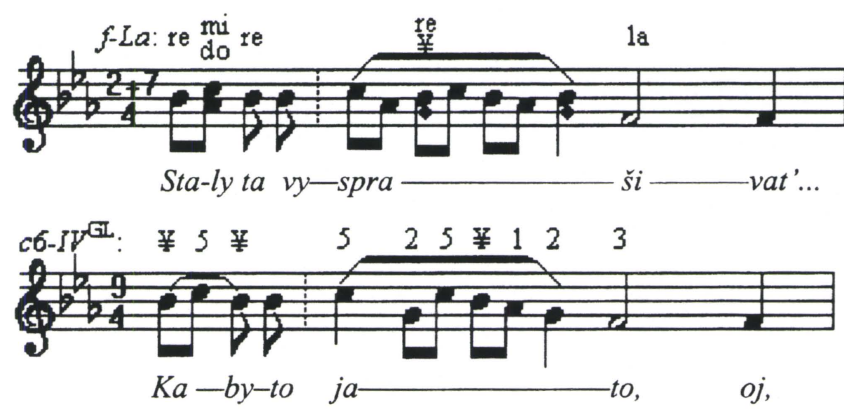

Figure 24. Two materialisations of the verse 2 in the stanzas 2 and 3 of the song in item I-10 (after Krasnopol'skaja 1987, pages 40-41). The upper line goes in $f$-La mode with $g^{1}$ as the auxiliary tone $¥$. The lower line goes in $c 6-I V^{\mathrm{GL}}$ with $b$ flat ${ }^{1}$ as its auxiliary $¥$.

\section{D.4. Fusion Melodies Dominated by the PIE Root VI ${ }^{G L}$}

The song of praise IV-47 is a tune characterised by the root $c^{1} 6-V I^{\mathrm{GL}}$ (Figure 25.A). On the other hand, the melody progresses like those in $f$-Sol pentatonic modality $\left(f^{1}\right.$ - 
$g^{1}-b b^{1}-c^{2}$ ). This is the case at the end of both verses. However, the main mode is clearly $V I^{\mathrm{GL}}$ and in such a way that the final tone is the basic tone $c^{2}$ of this mode. The same holds for the item IV-48 even though the Sol-mode is not as obvious. The finale is the 3rd degree of $V I^{\mathrm{GL}}$ and the sol of Sol mode. The upper voice of the song IV-49 (Figure 25.B) moves in tetrachordic $-d^{1}-e b^{1}-f^{1}-g^{1}$ while the lower part also visits tones $c^{1}$ and $b \mathrm{~b}$ making up a pentachord $b \mathrm{~b}-f^{1}$. The structure of melody suggests clearly the root $f 6-V I^{\mathrm{GL}}$ having the basic tone $f^{1}$ as the finale. It is, however, difficult to escape the sense of $b \mathrm{~b}-D o$-pentatonic flavour in the tune which might explain the tone $g^{1}=l a$ used once by the upper voice.

A:

$f-S O L$ : do $¥$ re do $¥$ la sol sol sol do la sol sol do $c 6-V I^{\mathrm{GL}}: \quad ¥ \quad 1 \quad 5 \quad ¥ \quad 1 \quad 2 \quad 3 \quad 3 \quad 3 \quad ¥ \quad \begin{array}{lllllll}1 & 2 & 3 & 3 & ¥\end{array}$

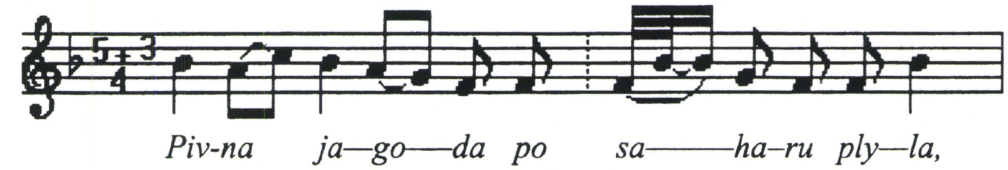

$f-S O L$ : do $¥$ re do re do $¥$ re do la la sol re $c 6-V I^{\mathrm{GL}}: \quad ¥ \quad \begin{array}{llllllllllll} & 5 & ¥ & 5 & ¥ & 1 & 5 & ¥ & 2 & 2 & 3 & 5\end{array}$

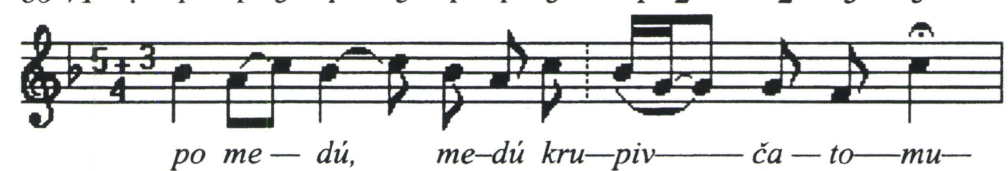

B:

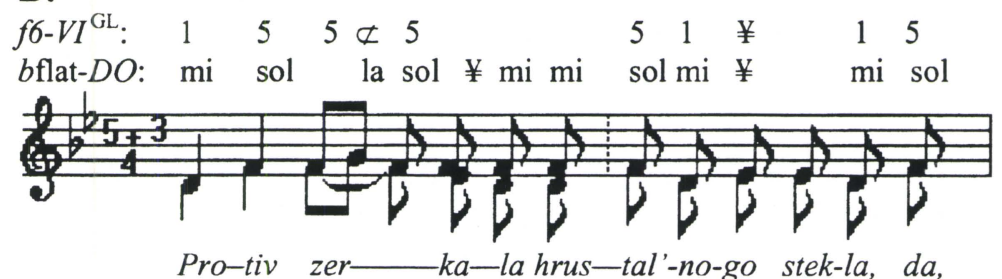

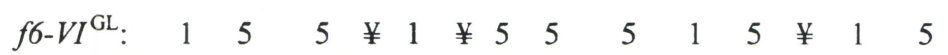
$b$ flat-DO: mi sol mi sol $¥ \mathrm{mi}$ re do do do sol $¥ \mathrm{mi}$ sol

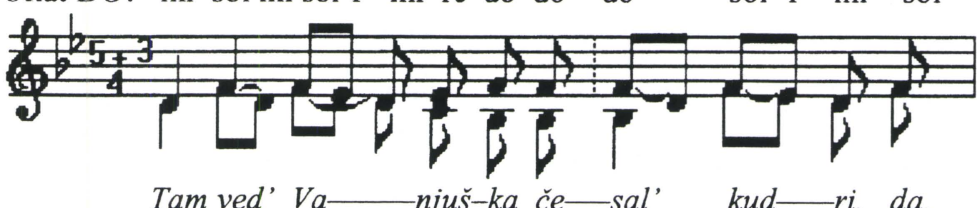

Figure 25. These wedding songs of praise are fusions of IE root $V I^{\mathrm{GL}}$ and anhemitonic structures.- $A$. An interesting combination of $c 6-V I^{\mathrm{GL}}$ and $f-L a$ pentatonic structures after Krasnopol'skaja 1987, IV-47, page 112. The pentatonic basic tone of $c 6-V I^{\mathrm{GL}}$ is always the finale tone of a stanza. (The rhythmic interpretation of the present author may not be quite correct on the syllables $s a$ - and -piv.) $-B$. This tune is a combination of elements from $f 6-V I^{\mathrm{GL}}$ (mainly upper voice) and $b$ flat-DO (mainly lower voice). Each verse of this iterative songs of praise ends on the pentatonic basic tone of $f 6-V I^{\mathrm{GL}}$. (After Krasnopol'skaja 1987, IV-49, page 114.) 


\section{E. On the History of the Transonegan Region}

The toponyms of the Onega district show that it was formerly populated by the Baltic Finnic, Lappish and even some of the westernmost Volga Finnic populations. There are Saame toponyms all over Karelia as well as in the St. Peterburg, Vologda, Archangel and Komi regions. During the 14th century the Onega region was populated both by Christian and pagan Baltic Finns and Lapps, and still in the 16th century the pagan Lapps were living in 7 "pogosts" in Central and North Karelia. (Kert et Mamontova 1976, 10-13 et passim; concerning the Veps, see Mullonen 1994.). The Viking Age Scandinavians knew Onega as *Ä̈̈ni (=Latin Ani) and the mountain where the Great warrior and magician Vísinn had his fortification was known as Anafial 'Anafjord' (= Fi. 'Äänisvuori'). A great Danish warrior Starkáðr was said to have sailed from the Gulf of Finland to Ruscia 'The Land of the Ruses' where Ani was situated. He killed Vísinn, sailed to Bizantium and from there to Polonia, as told by Saxo Grammaticus in his Gesta Danorum from 1180s (Saxo Grammaticus, Book 6, Frode IV (pages 228-229); about the interpretations, see Haavio 1965, 111-113.).

The sources for Saxo's history were the typical oral history of his time but this does not mean that the sources were unreliable fantasy. In this very case it seems as if the Anafial episode is a record of processes possibly occurred during the 8th century AD. The point is that the Danes had a clear knowledge of the presence of a prosperous region * $* \ddot{a} n i$ in northern Onega, and that they interacted with local peoples who defended themselves with a system of hill fortifications (also known up to West Finland) and having shamans as their leaders. The eponym Vísinn suggests clearly the easternmost Baltic Finnic population of the Vepses who - as we see - were culturally the middlemen between the Finno-Ugrians in Middle Volga and the Baltic Finns. Therefore, we might say that these Visinn-Vepses were an ancient group of people who were hunters and merchants mediating goods between the Urals and Scandinavia. They were known as Wizzi by Adam of Bremen in the 1070s and as Ves (from original Vepsi) in Old Russian sources. Many Baltic and Finno-Ugric populations on their eastern side had disappeared after switching language. The present "Russian"

populations between Lake Onega and Moscow are local conglomerates of Baltic populations, Finno-Ugrian tribes (Karelians, Vepses, Merjas, Meščeras and Muromas) and Slavic (Slovenic, Krivičic and Vjatičic) immigrants (see Figure 26).(Haavio 1965; Gimbutas 1971, especially 93-97.)

The East Slavic invasion into the Baltic and Finno-Ugric areas started during the late first millenium AD. The immigrants first settled down in regions not having permanent aboriginal inhabitants. During the 9th century the western Finno-Ugrians as well as the Slovenes paid taxes to Scandinavians and still then the regions of Belozersk, Rostov, Kostroma and Jaroslavl' were totally populated by Finno-Ugrians. The geo- 
political situation changed radically after the Slavic Krivicis and Slovenes and the Finno-Ugrian aboriginals (the Karelians, Vepses, Votes [ $=$ Chuds]) founded the independent state of Novgorod instead of the older town of Staraja Ladoga which was situated on the south of Lake Ladoga. All the populations who were internationally active in trade were called Rus by the outsiders. In present-day Europe it is only the Baltic Finns who use this word in its original meaning, that is, when referring to Sweden (Ruotsi < Old Swedish Ropars-lag 'The Rowers' League'). During the 10th century the Slavs took over all these nations politically, and after Vladimir of Kiev (d. 1015) had peoples under his rule baptised from 988 , the name Rus slowly became attached only to the Russian-speaking peoples in Russia. Still in those days the Onega area was populated by the Lapps and Baltic Finns, specifically by the Old Vepses, while the Old Karelians controlled regions north and west of them.

A:

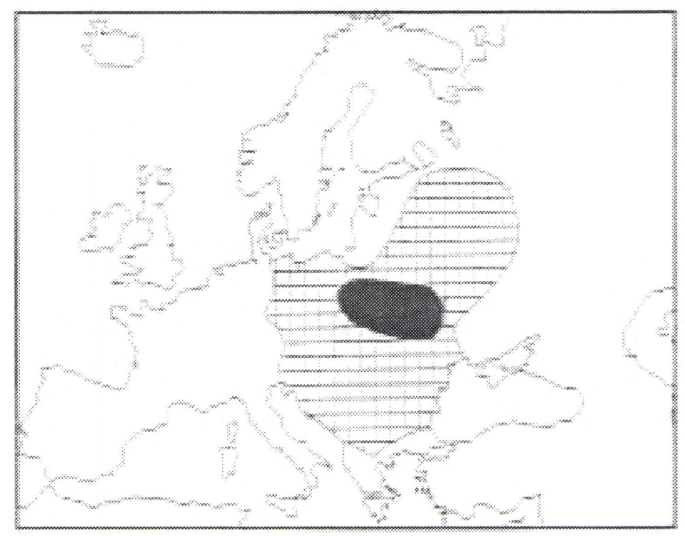

B:

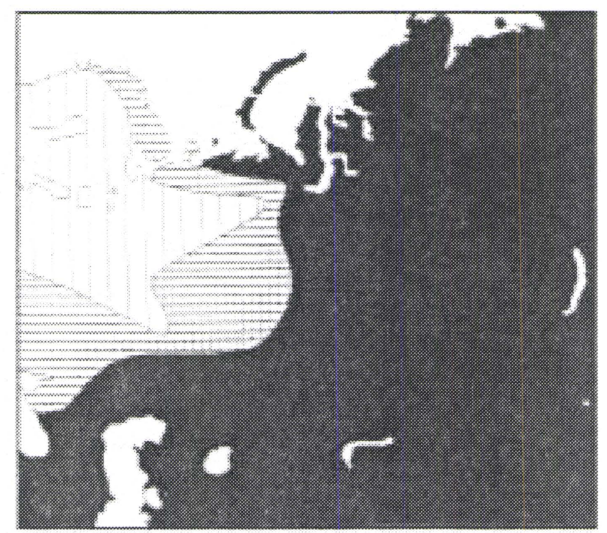

Figure 26. A. Areas effected by Slavic expansion before $600 \mathrm{AD}$ according to Niskanen 2000a, 55, Fig. 9. - B. A map of eye colour distribution according to Niskanen 2000b, 367, Fig.3. Vertical hatching refers to the area where most individuals have light eyes.

The Old Vepses were in close contacts with the Turkic Bolghars, Arabs and other merchants visiting the city of Bolghar presumably founded in the 7th century in the middle of the Finno-Ugric regions by the Bend of Volga. The Vepses were called Wisu in Arabic sources and it is quite obvious that they communicated since the late first millennium $\mathrm{AD}$ with the Bolghars via birch bark letters using an alphabet possibly based on Old Iranian writing (Stipa 1961, 359-360. Haavio 1965, 81-91). On the other hand, the Old Scandinavians were well acquainted with the Bjarms, the northern merchants around the large bay of the White Sea known as 'Dvina Sea' by Finns and Beloe more 'White Sea' by Russians. These northern Bjarms were prosperous dealers of fur who traded with Old Norwegians, too, who visited them by sailing along the Arctic Sea coastline. They seem to have been Karelians and Vepses but also 
some other Finno-Ugrians like the Komis (Zyrians). The Norwegians repeatedly mentioned Gandvik (< Karelian Kantalaksi) by the White Sea and the river Dvina to the east of it as the central places of their interactions with the Bjarms. During the early second millennium AD the Norwegians terrorised the Bjarms. The last war was conducted by Andrés Skjaldarbrand and Ívarr Útvik ca 1222, as reported in the Islandic saga Háttatal (Haavio 1965, 230-240). It was also Novgorod that had tried to capture the forests of the north-eastern Vepses since 1032, while the Vepses had tried to defend themselves by constructing a large system of hill fortifications since the early 11th century along with the rivers Dvina, Onega, Vaga, Suhona and Pinega. They were unable to protect themselves, however, and in the 1260s Novgorod troops took over the important mouth of the River Dvina, a former cult and market place of the Bjarms. Later on Middle Bjarmia has been know as the Archangel Region in Russia. When did the Transonegan people finally ceased speaking Finnic, is not known to the author. However, it may not have occurred until a few centuries ago.

The memory of these early peoples is still reflected, for instance, in the name of the River Volga. This name seems to be related to Veps volget 'light; white' a word that echoed in the name of Volgetjärv (Vougedjärv (Mullonen 1994, 133)) 'White Lake' = $\mathrm{Ru}$. Beloje ozero, one of the central areas of the former Vepses. (The same word is known as the Mari verb wolgaltes ' to get light; to dawn' and Finnish valko and valkea 'light; white'.) This Baltic Finnic system of naming wide and therefore luminous or 'light' lakes and rivers by this word seems to have been adopted by the Novgorod Slavs from their Veps-Karelian-Vote neighbours and the river name Volga diffused soon to the whole Russian-speaking area. On the other hand, Martti Haavio's hypothesis on the name Bjarmia is here taken seriously. It is genetically related to Old Scandinavian biarm 'radiance of light, not the light self' and bjarma 'to illuminate; grow light' both going back to Proto-Indo-European *bherek 'bright' (Haavio 1965, 46-48). The name Bjarmia is then basically analogic to modern English blond going back to Proto-Germanic *blund 'faintly shining' from Proto-Indo-European bhlndh-o (SEO: s.v. blond 1.). The point in Haavio's hypothesis is that the Bjarms were 'lightcoloured people'. This is, again, analogic to Celtic finn 'light coloured' and makes sense of the Old Russian stories of the Chuds with light-coloured eyes. Adam of Bremen also defined the Bjarms in Latin by writing: "Albani, qui lingua eorum Wizzi dicuntur". He had substituted the Nordic bjarm 'light-coloured' with Latin albus 'white; pale'. In English he wrote 'The white-coloured people who are called Wizzi [Vepsi] in their language'.

This historical introduction aims at illustrating two views. During the first and early second millennium AD the lake Onega region was populated by Saame and Baltic Finnic hunters and merchants. The formation of the present-day ethnic groups was in process which is why it is not easy to connect the past populations with the present ones with any certainty. It is, however, not even necessary. The main factors 
are that these people interacted with Scandinavians, the Volga Finns and the Turkic Bolghars, and that there was a continuous belt of Finno-Ugric peoples living from the Baltic Sea to the Urals. It was since the beginning of the second millennium when the East Slavic culture started to develop into Russian culture. This process took place while Finno-Ugrians stopped speaking their language after switching to East Slavic. As a result of this fusion Proto-Slavic culture received completely new cultural elements from the autochthonous peoples and Russian culture slowly emerged. However, around the Onega the Baltic Finns seem to have become Russians only since the 17 th century - which, however, remains an assumption.

\section{F. Tentative Conclusions}

The Transonegan region today may seem an outlying periphery. In earlier days it was an important district of Karelian merchants moving from west to east and north to south. E.g. still in the late 19th century the Onegan Russians had vivid connections with the Ladoga Karelians in the west. Without further research it is quite difficult to hazard any definite comments in general but from the point of music analysis there are some conclusions that can be made.

The Russian music tradition on the northern shores of Onega is composed of East Slavic and Baltic Finnic elements. The East Slavic inheritance is prominent for instance in wedding songs and long-drawn-out tunes. We can meet all the six ProtoIndo-European modal roots there. The pentatonic tradition is not strong as such but, typically of the Slavs, it can be detected in their late pentatonic derivatives which are either hexachords or their tetrachordic and pentachordic reductions. Quite a lot of melodies represent styles which seem to have been already in use during the late Neolithic and Bronze Age. These melodies go back to sources which were ancient already during the Proto Slavic time. They can be identified as Balto-Slavic and they evoke emotions in a listener parallel to those aroused by many Lithuanian and Latvian melodies. To put it shortly: the East Slavic tradition bears memories from Proto-IndoEuropean, Proto-Balto-Slavic and Proto-Slavic times. The main principle seems to be, roughly, that the narrower the ambitus of a tune, the younger is the tradition. However, the most ancient PIE pentatonic sets of rules govern all archaic singing of Slavic background even if a melody seems diatonic due to the arrangement of its four, five or six tones.

A surprising group of melodies are those which share stylistic elements with some styles typical of Central European German songs. The parallel features are rudimentary but identifiable. For instance, items IV-43, -44 and -45 are parallel with German medieval ballads with a refrain. However, the closing formulas are profoundly Rus- 
sian. There also are melodies with stylistic features that can be traced back to medieval West Europe. These similarities are so strong and obvious that it is impossible to ignore them. Therefore we are bound to presume that Transonegan singers had songs in their repertoire which were originally adopted from medieval musicians coming from Central and West Europe. These kinds of professional musicians were active in Russian cities and trade centres like Novgorod and Pskov, and it was during these periods the Russians also adopted, for instance, the word špil'man 'clown, actor, dancer, singer' from German spilman, spêlman (Fasmer, s.v. špil'man) probably before the 13th century. However, some other clues may suggest that certain similarities may spring from earlier sources than these because of the common modal structures covering all Indo-European singing.

Quite different seem those melodies having anhemitonic deep structure. It is the author's hypothesis that one part of folk song traditions in Russia is typically IndoEuropean but what makes Russian music unique in Europe is that part of its tradition which is a simultaneous fusion of hemitonic and anhemitonic traits. These kinds of conglomerate cannot be found in southern or western Slavic traditions. They are typically eastern. This can be explained by no other way than by assuming that the anhemitonic features are an inheritance from Finno-Ugrian singers who once lived in central and northern Russia, switched their languages but left a lot alive in their new culture. Some of their inputs to this new Russian culture were the anhemitonic elements governing the melody formation inside the otherwise hemitonic tradition of the East Slavs whose number was not always bigger in many areas in Russia than that of the locals. This is naturally nothing but a hypothesis, so far, but the fusion character is strikingly obvious. The author gives the reader one more example to make the point. A cadential formula which characterises the Russian folk song anywhere is:

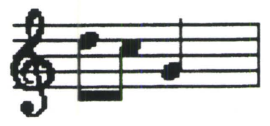

The movement is so simple that it feels quite trivial to mention it. The formula is, however, as if an identification signal of Russian song, and there must be a reason for that. It seems that there are many different ways to achieve this progression of three tones. In the domain of the IE modes $g-I^{\mathrm{GL}}, g-I I I^{\mathrm{GL}}, g-I V^{\mathrm{GL}}$ and $g-V I^{\mathrm{GL}}$ this descending progression corresponds to the movement 2-3-5. In the domain of the IE modes $d-I^{\mathrm{GL}}$, $d-I I I^{\mathrm{GL}}, d-I V^{\mathrm{GL}}$ and $d-V I^{\mathrm{GL}}$ the movement is $5^{2} ¥-3$. These can be found anywhere in Russia but this is not to explain the reason for its popularity. The main explanation seems to be the anhemitonic deep structure beneath the songs in early Russian music. The cadenza is basically a reminiscence of movement met with in Finno-Ugric traditions: 
$g-S O L$
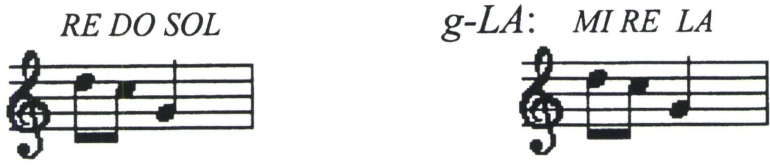

These two anhemitonic modes were favoured by the Finno-Ugric singers. The Sol mode is emotionally related to the IE roots $I^{\mathrm{GL}}$ and sometimes $V I^{\mathrm{GL}}$. The $L a$ mode is emotionally related mainly to the IE root $I V^{\mathrm{GL}}$ but sometimes to $I I I^{\mathrm{GL}}$, as well. There are no reasons to doubt a possibility that it was especially the Finno-Ugrian mothers ${ }^{5}$ who spoke the language of God and the Czars in their everyday life but sung songs to their children still having constructional elements from their anhemitonic background tradition. And because the roots $I^{\mathrm{GL}}, I I I^{\mathrm{GL}}$ and $I^{\mathrm{GL}}$ were in favour among the East Slavs these hemitonic and anhemitonic elements blended in most naturally. These processes could not occur effectively in any other area in Europe. The Russian style could therefore emerge only among the East Slavs.

The presence of anhemitonic elements in Transonegan traditions was not easy for the author to identify. As a good example is the lament VII-6 in Figure 27, transcribed in the 1880s in the village of Kuzoranda. The melody formation is non-Slavic in spite of its scalar structure which might come either from the root $e 6-I I I^{\mathrm{GL}}$ or $e 6-I V^{\mathrm{GL}}$. At the same time the melody feels characteristic of West Karelian laments. There are no problems at all in understanding the logic of this melody if we accept that the singer had the $L a$ pentatonic set of rules in mind. The melody progresses according to that and $b$ is nothing but an auxiliary tone $¥$. The melody could easily be sung without that tone: The architecture of the melody would still remain. This interpretation explains its inherently Baltic Finnic character. It also may give a hint to understanding the name Kuzoranda. In earlier days this coastal village was inhabited by Karelians who called it *Kuuziranda 'Fir Beach' or 'Spruce Strand'. It is as irrelevant to ask whether the auxiliary $¥$ is of Russian, Slavic or Pre-Slavic influence, as it is to ask whether $¥$ is the 2 nd degree of $I I I^{\mathrm{GL}}$ or of $I V^{\mathrm{GL}}$ ? It is ultimately non-Finno-Ugrian and a loan from the Indo-European side.

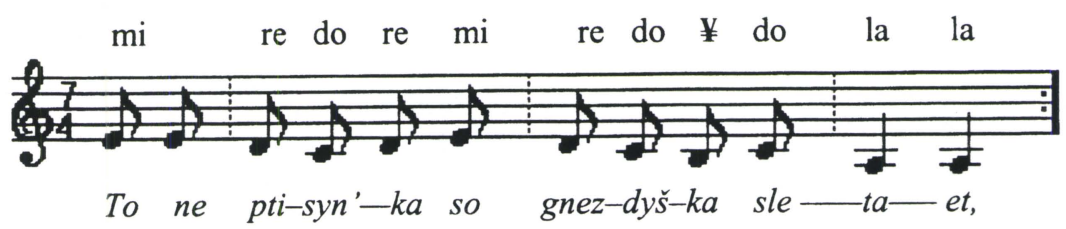

Figure 27. A lament in $a$ - $L a$ pentatonic modality having one auxiliary tone $¥$ (Krasnopol’skaja 1987, VII-6, page 151).

5 On the central role of mothers in the formation of fusion cultures, see Leisiö, Larisa 2001, 94. 
These processes of fusion took place during the past millennium or more in all parts of Russia. When the Russians invaded the Tansonegan district they naturally brought with them their (a) East Slavic and (b) Russian traditions. The processes of fusion continued there but now specifically through interaction with the Old-Veps, OldKarelian and South-Saame populations. It is not easy to say from which source came the quite obviously anhemitonic melodies like that in Figure 19.A. From the Veps or the Saame or Karelian? More detailed studies are needed. However, one fact is clear. The Karelian runo songs in Kalevala metre were based on the octosyllabic pattern and were sung syllabically. In Karelian laments the text was treated as in Russian longdrawn-out songs, that is, both in a syllabic and a melismatic way. Among many FinnoUgrians, instead of the strictly octosyllabic pattern there was a pattern of eight morae having four stressed and four unstressed positions. One mora was filled with one or more syllables. Practically this means that if we meet Transonegan songs characterised by syllabic style, we are not dealing with Veps or Saame traditions because the Kalevala metre did not belong to them.

Still in the 17th and 18th centuries Karelia (or the northern parts of Bjarmia according to the Old-Scandinavian terminology) stretched from present Dvina Karelia (east of Finland) to beyond the river Dvina in the modern region of Archangel, the contact area with Komi populations. As memories of former Baltic Finnic dwellers along the river Dvina we may find older place names also found in West Finland and West Karelia. Hence, we may presume that the runo style was a part of the culture of these northern people also living in the Transonegan areas in the south. Therefore the Karelian idioms in Transonegan singing may go back to the late Middle Ages as well as to the 17th century when Swedish imperialism forced most of the Greek Orthodox Karelians to move eastwards from the Finnish border areas.

The fusions of Slavic, Russian and Finnic elements are complex by nature. They are a fact, though. Many questions remain open and much research needs to be done.

\section{Bibliography}

Du, Yaxiong 1999. The La Pentatonic Scale and its Importance to Hungarian Prehistory Research. Tüzcsiholó, toim. Péter Pozsgai. Budapest: Kiadja a Táton Bt. Ss. 301-317.

Fasmer, Maks 1996. Etimologičeskij slovar' russkogo jazyka. Sankt-Peterburg: Terra. Gimbutas, Marija 1971. The Slavs. London: Thames and Hudson.

Haavio, Martti 1965. Bjarmien vallan kukoistus ja tuho. Porvoo-Helsinki: WSOY.

Habenicht, Gottfried 1977. Aus dem Liedgut des dobrudschdeutschen "Singers" Paul Ruscheinski. Quellen Deutscher Volkskunde. Band 6. Volkskunde-Tonarchiv Freiburg. Freiburg-im Breisgau.

Kádár, György 1999. Rinnasteinen ajattelutapa suomensukuisten kansojen musiikkiperinteessä. Jyväskylä: Jyväskylä Studies in the Arts 67.

Kert, G. \& N. Mamontova 1976. Zagadki karel'skoj toponimiki. Petrozavodsk: Izdatel'stvo Karelija. Kirkinen, Heikki 1990. Merjasta Mikkeliin. Kalevalaseuran vuosikirja 69-70, toim. Pekka Laaksonen ja Sirkka-Liisa Mettomäki. Helsinki: SKS. Ss. 242-265. 
Krasnopol'skaja, T. V.(toim.) 1987. Pesni Zaonežja v zapisjah 1880-1980 godov. Leningrad: Sovetskij kompozitor.

Launis, Armas 1908. Lappische Juoigos-Melodien gesammelt und herausgegaben von Armas Launis. Helsingfors: SKS Toimituksia XXVI.

Leisiö, Larisa 2001. Areaalikontakteja ja niiden seurauksia kielessä ja muussa kulttuurissa. Musiikin suunta $1 / 2001$. Helsinki, ss. 86-96.

Leisiö, Timo 1996. Metsäsuomalaisten varhaisia sävelmätallenteita Östmarkin pitäjästä, Värmlannista. Etnomusikologian vuosikirja 8, toim. Pirkko Moisala. Helsinki: Suomen etnomusikologinen seura. Ss. $163-221$.

Leisiö, Timo 1999a. Frühindoeuropäische Pentatonik und nordgermanischer Hexachord in der nordwesteuropäischen Musik.” Tüzcsiholó, toim. Péter Pozsgai. Budapest: Kiadja a Táton Bt. Ss. 245274.

Leisiö, Timo 1999b. Karjalan hääsävelmistön tyylihistoriaa. Musiikin suunta 3/1999. Helsinki. Ss. 4569.

Leisiö, Timo 2000a: Om tonalitetens ursprung och 'finskheten' i Sibelius musik. Hundra vägar har min tanke. Festkrift till Fabian Dahlström, toim. Glenda Goss et al. Porvoo-Helsinki: WSOY. Ss. 3360.

Leisiö, Timo 2000b. Laulujen kommentaarit / Magyarázatok a dalakról. Mentem eprészni erdõre, áfonyázni rengetegbe, toim. György Kádár, Jaakko Kellosalo and Eija Kukkurainen. Szombathely: Minoritates Mundi - Literatura, szerkeszti János Pusztay. Ss. 186-233.

Leisiö, Timo 2001: Indoeurooppalaisesta pentatoniikasta tonaalisuuteen. Teoria musiikillisen ajattelun muutoksista Euroopassa. Muualla, täällä. Kirjoituksia elämästä, kulttuurista, musiikista. Toim. Helena Tyrväinen et al. Jyväskylä. Atena Kustannus. Ss. 252-368.

Leisiö, Timo in print. On Old-Lithuanian Modalities: A Hypothesis on Five Stylistic Strata Based on Proto-Indo-European Pentatonic Roots. (A publication to come out in Vilnius under the edition of Rimantas Astrauskas.)

Lükö, Gábor 1964: "Zur Frage der Musikkultur in der slawischen Urzeit.” Budapest: Studia Slavica Academice Scientiarum Hungarica. Tomus X, Fasciculi 4-3. Ss. 237-289.

Lükö, Gábor 1965: "Vestiges indo-européens dans le folklore musical des peuples finno- ougriens." Paris: Études finno-ougriennes. Tome II. Fasc. 1.

MMAR: Music of the Middle Ages and the Renaissance. Volume II. EMI 1986: HQS 1196.

Mullonen, I[rma]. 1994. Očerki vepsskoj toponimii. Sankt-Peterburg: "Nauka".

Niskanen, Markku 2000a. The Origin of Europeans: Population Movements, Genetic Relationships and Linguistic Distribution. The Roots of Peoples and Languages of Northern Eurasia II and III, toim. A. Künnap. Tartu: Fenno-Ugristica. Ss. 33-59.

Niskanen, Markku 2000b. Somatological Variation and the Population History of Northern Eurasia. The Roots of Peoples and Languages of Northern Eurasia II and III, toim. A. Künnap. Tartu: FennoUgristica. Ss. 349-210.

Saxo Grammaticus 1985. Danmarks Krønike. Viborg.

SEO 1980. Svensk etymologisk ordbok af Elof Hellquist I-II. Lund: LiberLäromedel.

Stipa, Günther 1961: Der Ursprung der permischen Schrift. Zeitschrift der Deutschen Morgenländischen Gesellschaft. Band 110. Wiesbaden.

Szomjas-Schiffert, György 1990. Descending Quintine Shift Construction in the Finnish Music. Congressus Septimus Internationalis Fenno-Ugristarum 4. Sessiones Sectionum. Debrecen. Ss. 202210.

Tampere, Herbert 1965. Eesti rahvalaule viisidega V. Tallinn: Kirjastus Valgus.

Zemcovsky, Izaly 1967. Russkaja protjažnaja pesnja. Leningrad: Muzyka.

Zemtsovsky, Izaly 2000. Russia. Europe. The Garland Encyclopedia of World Music. Volume 8, toim. Timothy Rice, James Porter \& Chris Goertzen. New York - London: Garland Publishing, Inc. Ss. 754-789.

Wiik, Kalevi 2000. European Lingua Francas. The Roots of Peoples and Languages of Northern Eurasia II and III, toim. A. Künnap. Tartu: Fenno-Ugristica. Ss. 202-236. 